\title{
Chromatic Organization of Ganglion Cell Receptive Fields in the Peripheral Retina
}

\author{
Samuel G. Solomon, ${ }^{1}$ Barry B. Lee, ${ }^{2,3}$ Andrew J. R. White, ${ }^{1}{ }^{L}$ ukas Rüttiger, ${ }^{2}$ and Paul R. Martin ${ }^{1,4,5}$ \\ ${ }^{1}$ Department of Physiology F13, The University of Sydney, Sydney, New South Wales 2006, Australia, ${ }^{2}$ Department of Neurobiology, Max Planck Institute \\ for Biophysical Chemistry, D-37077 Göttingen, Germany, ${ }^{3}$ College of Optometry, State University of New York, New York, New York 10036, ${ }^{4}$ National \\ Vision Research Institute of Australia, Carlton, Victoria 3053, Australia, and ${ }^{5}$ Department of Optometry and Vision Sciences, The University of Melbourne, \\ Melbourne, Parkeville 3052, Australia
}

This study addresses the chromatic properties of receptive fields in the subcortical visual pathway of primates. There is agreement that, in the central visual field, many cells belonging to the parvocellular (PC) division of the subcortical pathway show red-green opponent responses, that a subgroup of cells belonging to the koniocellular $(\mathrm{KC})$ pathway shows blue-yellow opponent responses, and that magnocellular (MC) pathway cells show only weak signs of chromatic input. However, the chromatic properties of ganglion cells in the peripheral retina are poorly understood. Here, we measured the temporal-chromatic properties of ganglion cells in extracellular in vivo recordings from peripheral macaque retina. We show that the chromatic responsivity of peripheral KC ("blue-on") and MC cells is very similar to that of their counterparts in the foveal retina. Cone-opponent responses are expressed only at low temporal frequencies $(<10$ $\mathrm{Hz}$ ) in the majority of peripheral PC cells, and some peripheral PC cells show non-opponent response properties. With these exceptions, the chromatic properties of ganglion cells are essentially preserved throughout the first $50^{\circ}$ of visual eccentricity. The main change seen in passing from foveal to peripheral retina is that all ganglion cell classes become more responsive to high temporal-frequency modulation.

Key words: color vision; primate; visual field; parvocellular; magnocellular; koniocellular

\section{Introduction}

The responses of many ganglion cells in the primate retina and in the parvocellular (PC) layers of the lateral geniculate nucleus are consistent with antagonistic (cone-opponent) interaction between medium-wavelength-sensitive (M or "green") and longwavelength-sensitive (L or "red") cone photoreceptors (Wiesel and Hubel, 1966; Dreher et al., 1976; Derrington et al., 1984; Reid and Shapley, 2002). Cone-opponent responses in PC cells are thought to arise from at least partial segregation of M- and L-cone signals to receptive field "center" and "surround" (Wiesel and Hubel, 1966; Gouras and Zrenner, 1979; Smith et al., 1992; Reid and Shapley, 2002). A second population of cone-opponent cells ("blue-on" cells) shows responses consistent with excitation from short-wavelength-sensitive (S or "blue") cones and oppo-

Received Sept. 22, 2004; revised March 21, 2005; accepted March 21, 2005.

This work was supported by Australian National Health and Medical Research Council (NHMRC) Grant 253621 and National Eye Institute Grant 13112.S.G.S. was supported by a University of Sydney Faculty of Medicine postgraduate research scholarship. A.J.R.W. was supported by an NHMRC Dora Lush award. Travel support was provided by the University of Sydney Tapping Bequest (A.J.R.W.) and by a University of Sydney Faculty of Medicine traveling scholarship (S.G.S.). We thank T. R. Vidyasagar and the anonymous reviewers for comments on this manuscript and V. C. Smith for valuable advice on cell modeling.

Correspondence should be addressed to Paul R. Martin, National Vision Research Institute of Australia, Corner Keppel and Cardigan Streets, Carlton, Victoria 3053, Australia. E-mail: prmartin@unimelb.edu.au.

S. G. Solomon's present address: University Laboratory of Physiology, The University of Oxford, Parks Road, Oxford, OX1 3PT, UK.

L. Rüttiger's present address: Tübingen Hearing Research Center, University Clinic, Elfriede-Aulhorn-Strasse 5, D-72076 Tübingen, Germany.

DOI:10.1523/JNEUROSCI.3921-04.2005

Copyright $\odot 2005$ Society for Neuroscience $\quad$ 0270-6474/05/254527-13\$15.00/0 nent input from a mixture of $\mathrm{M}$ and $\mathrm{L}$ cones. Blue-on cells are thought to derive opponent cone inputs through depolarizing (blue-on) and hyperpolarizing ("yellow-off") bipolar pathways (Gouras, 1968; De Monasterio and Gouras, 1975; Dacey and Lee, 1994; Calkins et al., 1998; Ghosh and Grünert, 1999). Blue-on cells contribute to the koniocellular (KC) subdivision of the afferent visual pathway (Martin et al., 1997; Hendry and Reid, 2000).

Although responses of neurons in the magnocellular (MC) afferent visual pathway are dominated by summed $\mathrm{M}$ - and L-cone inputs, MC cells also show weak signs of chromatic input. This was first noted by Wiesel and Hubel (1966) who observed that the firing of MC cells was inhibited when "the field was flooded with red light" and was confirmed by later studies (Schiller and Malpeli, 1977; De Monasterio and Schein, 1980; Smith et al., 1992). The source of this opponent signal is unknown.

Most studies to date have characterized receptive fields located near the fovea. It is unclear whether the chromatic organization of peripheral retina parallels that outlined above. One previous in vivo study found high red-green (RG) chromatic sensitivity in peripheral PC cells (Martin et al., 2001), but, on the basis of recordings from an in vitro preparation, Diller et al. (2004) concluded that peripheral PC cells show almost exclusively non-opponent combination of M- and L-cone inputs. Furthermore, the chromatic properties of peripheral MC and $\mathrm{KC}$ (blue-on) cells have not been measured quantitatively. Resolu- 
tion of these questions is important for understanding the variation of human color vision across the visual field.

In the present study, we addressed these questions by making several sets of measurements. First, we measured responses of PC and $\mathrm{MC}$ cells to the relative phase of heterochromatically modulated lights, using stimuli identical to those used previously to study PC cell responses in foveal retina (Smith et al., 1992). Second, we measured PC cell sensitivity to chromatic and luminance (LUM) temporal contrast and developed a temporal-chromatic receptive field model to account for changes in cell sensitivity with retinal eccentricity. Third, we measured sensitivity to spatial contrast in PC cells in peripheral retina to seek evidence for spatial segregation of opponent inputs to the receptive field. Finally, we measured the spatial and temporal properties of blue-on $\mathrm{KC}$ cells in peripheral retina.

\section{Materials and Methods}

Extracellular recording. Intraocular recordings were made from the eyes of three male and two female adult macaque monkeys (Macaca fascicularis) using procedures described previously (Smith et al., 1992). Animals were obtained from the German Primate Center (Göttingen, Germany). We do not know the pedigree of the animals used, but it is unlikely that they were related because the colony is regularly replenished from several Asian suppliers. No obvious differences between the properties of cells were apparent when different animals were compared. All procedures are approved by the Animal Care Committee of the state of Lower Saxony and the State University of New York Optometry Animal Care and Use Committee and conform to the Society for Neuroscience policy on the use of animals in neuroscience research. Animals were anesthetized initially with intramuscular ketamine $(\sim 20 \mathrm{mg} / \mathrm{kg})$ and then thiopental (10 $\mathrm{mg} / \mathrm{kg}$ ). Subsequently, anesthesia was maintained by $1-2 \%$ isoforene in the inspired gas mixture. A venous infusion of $5 \mathrm{mg} \cdot \mathrm{kg}^{-1} \cdot \mathrm{h}^{-1}$ gallamine triethiodide in dextrose Ringer's solution was used to maintain muscular paralysis. The animal was respired with a 70:30\% mixture of $\mathrm{NO}_{2} / \mathrm{O}_{2}$. The electroencephalogram and electrocardiogram were monitored to ensure adequate depth of anesthesia. End-tidal $\mathrm{P}_{\mathrm{CO}_{2}}$ was kept between 4 and $5 \%$, and body temperature was maintained near $37.5^{\circ}$. A gas-permeable rigid contact lens with internal radius matched to the corneal curvature was used to focus the eye on a tangent screen at a distance of $114 \mathrm{~cm}$. The positions of the fovea and optic disk were marked on the screen with the aid of a rear-projecting fundus camera. A cannula was inserted through the sclera, just behind the limbus. A tungsten microelectrode was lowered through this cannula onto the retina, and extracellular action potentials originating from a single ganglion cell were isolated. To test antidromic activation latencies of ganglion cells, a pair of stimulating electrodes was inserted through a small craniotomy and implanted in the optic chiasm (28 $\mathrm{mm}$ anterior, $2 \mathrm{~mm}$ lateral, $\sim 26 \mathrm{~mm}$ below cortical surface). Cells were initially classified by their responses to hand-held stimuli and the antidromic activation latency and thereafter using the stimuli described below. The time of occurrence of action potentials was measured with an accuracy of $0.1 \mathrm{~ms}$. Response amplitude was taken as the first Fourier harmonic amplitude at the stimulus frequency. Peristimulus time histograms (PSTHs) were constructed from at least $6 \mathrm{~s}$ of presentation for each stimulus.

Clarity of the optic media was monitored, and, if the smaller retinal vessels could no longer be recognized (usually after $48-72 \mathrm{~h}$ ), the recording from that eye was terminated. Recordings were normally made from both eyes in each experiment. On completion of recording, the animal was killed with an overdose of barbiturate.

Visual stimuli. The chromatic-temporal signal transfer properties of ganglion cells were measured using a three-channel Maxwellian view system, as fully described previously (Smith et al., 1992). Briefly, the stimulus at the retinal plane comprised a spatially uniform field of $4.7^{\circ}$ diameter, derived from three light-emitting diodes (LEDs) with dominant wavelengths at $638 \mathrm{~nm}$ (red), $554 \mathrm{~nm}$ (green), and $470 \mathrm{~nm}$ (blue). The $470 \mathrm{~nm}$ LED was mainly used for testing blue-on cells; for other neurons, the measurements were made using only the 638 and $554 \mathrm{~nm}$
LEDs. Time-averaged retinal luminance was normally close to $2000 \mathrm{hu}-$ man trolands. The LEDs were driven under computer control through custom circuitry, which uses pulse-train frequency modulation to achieve a linear relationship between driving voltage and LED intensity. This system is referred to hereinafter as the LED stimulator. In terms of Michelson contrast, 100\% "red-green chromatic" modulation corresponded to $68 \%$ contrast in the M cone and $20 \%$ contrast in the L cone (Smith et al., 1992). Two additional stimuli were used to study the properties of blue-on cells. For both stimuli, the 470 and 638 nm LEDs were modulated in counter phase with the $554 \mathrm{~nm}$ LED. For the first condition ("S-cone isolating"), the relative intensity was adjusted to selectively modulate the $\mathrm{S}$ cones. This stimulus produced $98 \%$ contrast in $\mathrm{S}$ cones and $<1 \%$ in the $\mathrm{M}$ and $\mathrm{L}$ cones. For the second condition ("silent-S"), the intensity was adjusted to modulate the $\mathrm{M}$ and $\mathrm{L}$ cones in-phase at 44 and $78 \%$ respectively, with negligible S-cone modulation.

Spatial properties of receptive fields were measured using drifting (4.3 $\mathrm{Hz}$ ) sinusoidal gratings generated by a VSG (video signal generator) series three computer (Cambridge Research Systems, Cambridge, UK) and presented at a frame frequency of $195 \mathrm{~Hz}$ on a Reference Calibrator Plus CRT Monitor (Barco Systems, Kortrijk, Belgium). This system is referred to hereinafter as the CRT (cathode ray tube) stimulator. The viewing distance was $114 \mathrm{~cm}$. Properties of PC-pathway cells were assessed using gratings generated with the red and green guns of the CRT stimulator. The green gun intensity was scaled to match the $10^{\circ} V_{l}$ luminance of the red gun intensity. The red and green components of the grating were presented in either opposite spatial phase to produce redgreen isoluminant modulation or the same spatial phase to produce yellow-black luminance modulation. In terms of Michelson contrast, $100 \%$ chromatic modulation corresponded to $12 \%$ contrast in the L cone and $28 \%$ contrast in the $\mathrm{M}$ cone. The luminance modulation contrast was normally set to $100 \%$ for PC cells and $25 \%$ for MC cells but was reduced for cells that showed significant response saturation, as reported previously (Solomon et al., 2002). To study the spatial properties of blue-on cells, two types of cone-isolating gratings were used. The first (S-cone isolating) was designed to selectively modulate the $\mathrm{S}$ cones. It produced $86 \%$ contrast in $\mathrm{S}$ cones and $<1 \%$ in the $\mathrm{M}$ and $\mathrm{L}$ cones. The second (silent-S) modulated the $\mathrm{M}$ and $\mathrm{L}$ cones at 79 and $40 \%$, respectively, and the $\mathrm{S}$ cone at $4 \%$. Photometric properties of the LEDs and the CRT monitor were measured with a spectrophotometer (model pro-703/ PC; Photo Research, Palo Alto, CA).

Measurements. Three sets of measurements were usually made on each cell. First, we used the LED stimulator to record responses to red and green LED modulation at 16 relative LED phases over the temporalfrequency range between 1.22 and $39.04 \mathrm{~Hz}$ (the "phase paradigm"). Second, we measured contrast sensitivity for in-phase (luminance) or out-of-phase (red-green chromatic) LED modulation at 12 frequencies between 0.61 and $78 \mathrm{~Hz}$. Third, we used the CRT stimulator to measure responses to red-green chromatic and luminance spatial contrast at a series of spatial frequencies between 0.01 and 10 cycles per degree. For blue-on cells, we measured temporal and spatial modulation transfer functions for S-cone isolating and silent-S stimuli. Some PC and MC cells were also tested with these stimuli. A subset of PC $(n=15)$ and MC $(n=$ 20 ) cells was also tested for linearity of spatial summation, using counter phase $(4.3 \mathrm{~Hz})$ modulated luminance gratings at close-to-optimal spatial frequency, presented at 12 spatial phases spanning $360^{\circ}$. The nonlinearity index (NLI) was determined from the maximum first-harmonic amplitude divided by the average second-harmonic amplitude (White et al., 2002).

Receptive field dimensions were estimated from the spatial modulation transfer functions, by fitting response amplitude with a differenceof-Gaussians (DOG) function expressed in the frequency domain (Enroth-Cugell and Robson, 1966; Derrington and Lennie, 1984):

$$
R=C\left(K_{c} \pi r_{c}^{2} e^{-\left(\pi r_{c}\right)^{2}}-K_{s} \pi r_{s}^{2} e^{-\left(\pi r_{s}\right)^{2}}\right),
$$

where $R$ is the response amplitude (impulses per second), $C$ is the Michelson contrast of the stimulus, and $f$ is the spatial frequency of the stimulus. The free parameters $K_{c}$ and $K_{s}$ (peak sensitivity of center and surround mechanisms) and $r_{c}$ and $r_{s}$ (radius of center and surround 
mechanism) were optimized by minimizing the mean square error (MSE) between the data and the model using a Levenberg-Marquardt routine (Matlab optimization toolbox; MathWorks Natick, MA).

Modeling of phase paradigm data. Following Smith et al. (1992), the response vector (amplitude and phase) of each cone type is derived by vector addition of cone excitation to the red and green LEDs, and then the cell response is predicted by vector combination of these cone inputs. All phases are referenced to the phase of the red LED. For the M cone, the response vector $(\vec{M})$ is as follows:

$$
\vec{M}=\vec{R}_{M}+\vec{G}_{M} e^{i \theta},
$$

where $\vec{R}_{M}$ is the amplitude and phase of response to the red LED, $\vec{G}_{M}$ is the amplitude and phase of response to the green LED, $e$ is the natural exponent, $\theta$ is the phase of the green LED, and $i$ is the imaginary unit $\sqrt{-1}$. The L-cone excitation is calculated in the same way. The response of a cone-opponent cell $\vec{C}$ is predicted from a weighted sum of these input vectors, with additional delay terms for each opponent mechanism. For cells that receive center input from M cones ("green-on" and "green-off" cells), the predicted response is as follows:

$$
\vec{C}=A\left[W \vec{M} e^{i \theta_{M}}+(1-W) \vec{L} e^{i \theta_{L}}\right],
$$

where $\vec{C}$ is cell phase and amplitude, $A$ is an amplitude scaling factor, $W$ is the M-cone weight, $\vec{M}$ and $\vec{L}$ are the cone response vectors from Equation 2, $\theta_{M}$ is the center (M-cone) delay, and $\theta_{L}$ is phase of the $\mathrm{L}$ cone incorporating a surround delay (Smith et al., 1992). Cell responses were fit to this model, with free parameters $A, W, \theta_{M}$, and $\theta_{L}$. The M/L-cone balance parameter $(W)$ was constrained to lie between 0 and 1 . Other parameters were unconstrained. Response amplitude and phase for each grating was fit to the predicted cone contrast by minimizing the MSE between the data and the model as described above. The relative weight of phase and amplitude errors was adjusted so that one impulse per second was equivalent to $5-10^{\circ}$ phase error. This ratio gave the most efficient and reliable convergence for the great majority of stimulus conditions. In a small number of cases in which response amplitude was low, greater weight was given to the phase error to allow the fit to converge. To avoid convergence to local minima in the error function, parameters were given initial values within the range of feasible solutions (Smith et al., 1992; Yeh et al., 1995b).

Modeling of luminance and chromatic PC-cell temporal response. The contrast sensitivity of receptive fields in the subcortical visual system has been modeled with variations on a linear filter cascade (Frishman et al., 1987; Benardete and Kaplan, 1997; Lankheet et al., 1998). We elaborated one of these models (Smith et al., 2001), first developed for cat retinal ganglion cells (Frishman et al., 1987), to incorporate the spectral opponent properties of PC cells. The amplitude and phase of cone modulation was estimated using Equation 2, with the green LED phase set to $0^{\circ}$ (luminance modulation) or $180^{\circ}$ (chromatic modulation). The center response was modeled by assuming that a single cone type provides excitatory input. Therefore, for red-on and red-off cells,

$$
\begin{aligned}
C_{\text {resp }}=L_{\text {resp }}\left\lfloor\left\{\frac{\left(1+i \alpha 2 \pi f t_{\alpha}\right)^{2}}{\left(1+i 2 \pi f t_{\alpha}\right)^{2}}\right\}\left(1+i 2 \pi f t_{L}\right)^{-N_{1}}\right. \\
\left.\qquad\left\{1+\frac{\left(i 2 \pi f t_{h}\right)}{\left(H+i 2 \pi f t_{h}\right)}\right\} e^{\left(i 2 \pi f D_{c}\right)}\right\rfloor,
\end{aligned}
$$

where $L_{\text {resp }}$ is the response of the $\mathrm{L}$ cone to the stimulus, $\alpha$ and $t_{\alpha}$ are strength and the time constant (milliseconds) of a lead-lag filter, $N_{l}$ and $t_{L}$ are the number of stages and the time constant of a low-pass filter cascade, $H$ and $t_{h}$ are the weight and time constant of a second-order filter, and $D_{C}$ is a pure delay for the center. The lead-lag filter is intended to represent adaptation mechanisms in the photoreceptors. The secondorder filter is intended to represent the resonance or feedback mechanisms that occur in the pre-ganglion cell synaptic circuitry. The low-pass filter cascade represents a combination of the photoreceptor lightresponse cascade and the time constants of pre-ganglion cell synapses.

We allowed a variable spectral mixture to the surround. The relative

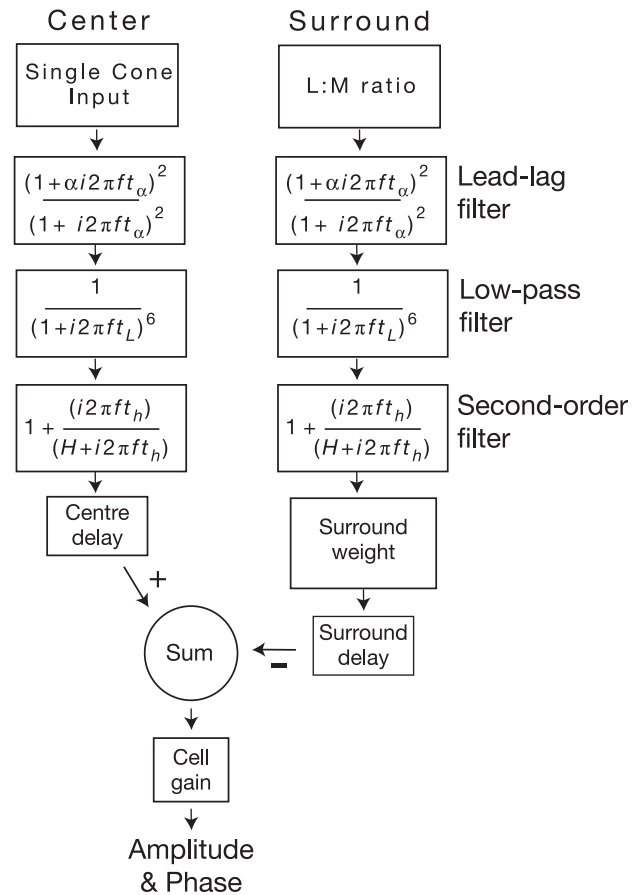

Figure 1. Schematic summary of the linear filter cascade model described in Materials and Methods.

cone weight in the surround $\left(S_{W}\right)$ represents the ratio of $\mathrm{L} / \mathrm{M}$ cones, by the following equation:

$$
S_{W}=W L_{\text {resp }}+(1-W) M_{\text {resp }},
$$

where $M_{\text {resp }}$ is the response of the $M$ cone from Equation 2. The response of the surround is, therefore, as follows:

$$
\begin{aligned}
& S_{\text {resp }}=S_{W}\left\lfloor\left\{\frac{\left(1+i \alpha 2 \pi f t_{\alpha}\right)^{2}}{\left(1+i 2 \pi f t_{\alpha}\right)^{2}}\right\}\left(1+i 2 \pi f t_{1}\right)^{-N_{1}}\right. \\
&\left.\left\{1+\frac{\left(i 2 \pi f t_{h}\right)}{\left(H+i 2 \pi f t_{h}\right)}\right\} e^{\left\{i 2 \pi f\left(D_{c}+D_{s}\right)\right\}}\right\rfloor,
\end{aligned}
$$

where $D_{S}$ is the delay of the inhibitory mechanism additional to that of the excitatory center. The cell output $R$ is given by the following:

$$
R=A\left[C_{w} C_{\text {resp }}+\left(1-C_{w}\right) S_{\text {resp }}\right],
$$

where $A$ is an amplitude scaling factor, and $C_{w}$ is the center weight. We fit this function in the complex plane to both chromatic and luminance data, as described above for analysis of responses to the phase paradigm. For each temporal frequency, cell response gain was estimated from the initial slope of a Naka-Rushton function (with exponent set to 1) fit to the contrast-response relationship (Solomon et al., 2002). Response phase was measured from the first contrast level that elicited a response of $>10$ impulses per second.

Initial fits were made with the full model to establish which parameters could be fixed without significant increase in residual error. We fixed the pure delay of the center to $10 \mathrm{~ms}$ and the number of stages in the low-pass filter cascade $\left(N_{l}\right)$ to six. These simplifications reduced the free parameters to $\alpha, t_{\alpha}, t_{L}, H, t_{h}, D_{S}, C_{W}, A$, and $W$, a total of nine (and thus $15 \mathrm{df}$ in the complex domain). The final model is summarized in Figure 1.

\section{Results}

We first compare the chromatic and luminance responsivity of $\mathrm{PC}$ cells in foveal and peripheral retina. We then analyze the frequency dependence of responses to luminance and chromatic 
temporal modulation and show how systematic changes in a small number of parameters can account for the differences seen between foveal and peripheral PC-cell responses. In addition, we show that properties of MC cells in peripheral retina are consistent with a weak chromatic input, as shown previously for foveal MC cells. Finally, we show that the temporal-chromatic and spatial properties of blue-on cells are essentially preserved in the peripheral retina.

\section{Cell classification}

We recorded from 131 ganglion cells with receptive fields located between $20^{\circ}$ and $47^{\circ}$ eccentricity. Receptive fields were located almost exclusively in the inferior retina. Nineteen cells were classified as blue-on cells. Nearly all of the other cells could be classified as phasic, MC cells or tonic, or PC cells by their responses to hand-held stimuli. Assessment of the (tonic or phasic) response to maintained achromatic contrast gave the most straightforward basis for classification, and the initial classification was almost invariably borne out by the quantitative analysis.

The results presented here are based on quantitative analysis of responses in 16 blue-on cells, $66 \mathrm{MC}$ cells, and $36 \mathrm{PC}$ cells with receptive fields above $20^{\circ}$ eccentricity; most of these cells were tested using all three stimulus paradigms as described above (see Materials and Methods). We reported previously on chromatic modulation sensitivity of peripheral PC cells (Martin et al., 2001; Solomon et al., 2002); these and additional data from the same cell sample were used as the basis for cell modeling in the present study. We also reanalyzed data from previous studies using the LED stimulus paradigms (Lee et al., 1990, 1994; Smith et al., 1992; Kremers et al., 1993). These data were obtained from receptive fields within the central $15^{\circ}$; most of these fields $(68 \%)$ were within $5^{\circ}$ of the fovea. We saw no clear trends in chromatic response properties within the range of $0-15^{\circ}$. In the following, we refer to this data set as foveal data, but the reader should note that the term foveal is not strictly accurate for a few of the receptive fields in this category.

Control observations from a small number of foveal cells recorded in the present study showed no systematic differences with these previous studies, so the data were pooled.

\section{Overview of cell properties}

During recordings from peripheral retina, it became apparent that $\sim 30 \%$ of the cells with the long antidromic latency characteristic of PC cells (De Monasterio and Gouras, 1975) showed no overt signs of red-green opponency. As shown in Figure 2A, almost all PC cells have longer latencies (mean $\pm \mathrm{SD}, 8.2 \pm 1.3$ $\mathrm{ms} ; n=28$ ) than MC cells (mean $\pm \mathrm{SD}, 4.6 \pm 0.7 \mathrm{~ms} ; n=68 ; p<$ 0.02 ; Wilcoxon's rank-sum test), making it unlikely that MC cells could be mistaken for non-opponent PC cells. Apart from the variability in responses to red-green modulation (described further below), the peripheral PC cells formed a functionally homogeneous population. Figure 2, $B$ and $C$, shows responses to luminance and chromatic gratings for two peripheral PC cells recorded from the same eye. The receptive field positions of these cells are indicated with arrows in Figure $2 \mathrm{~A}$. Responses to lowcontrast $(25 \%)$ luminance modulation are shown together with responses to $100 \%$ chromatic modulation. As noted above (see Materials and Methods), the chromatic grating produced $\sim 28 \%$ modulation in the $\mathrm{M}$ cone and $\sim 12 \%$ modulation in the $\mathrm{L}$ cone. For the opponent PC cell shown in Figure $2 B$, response amplitude for chromatic modulation exceeds the response amplitude for luminance modulation for nearly all of the spatial frequencies tested. The luminance response shows a bandpass modulation
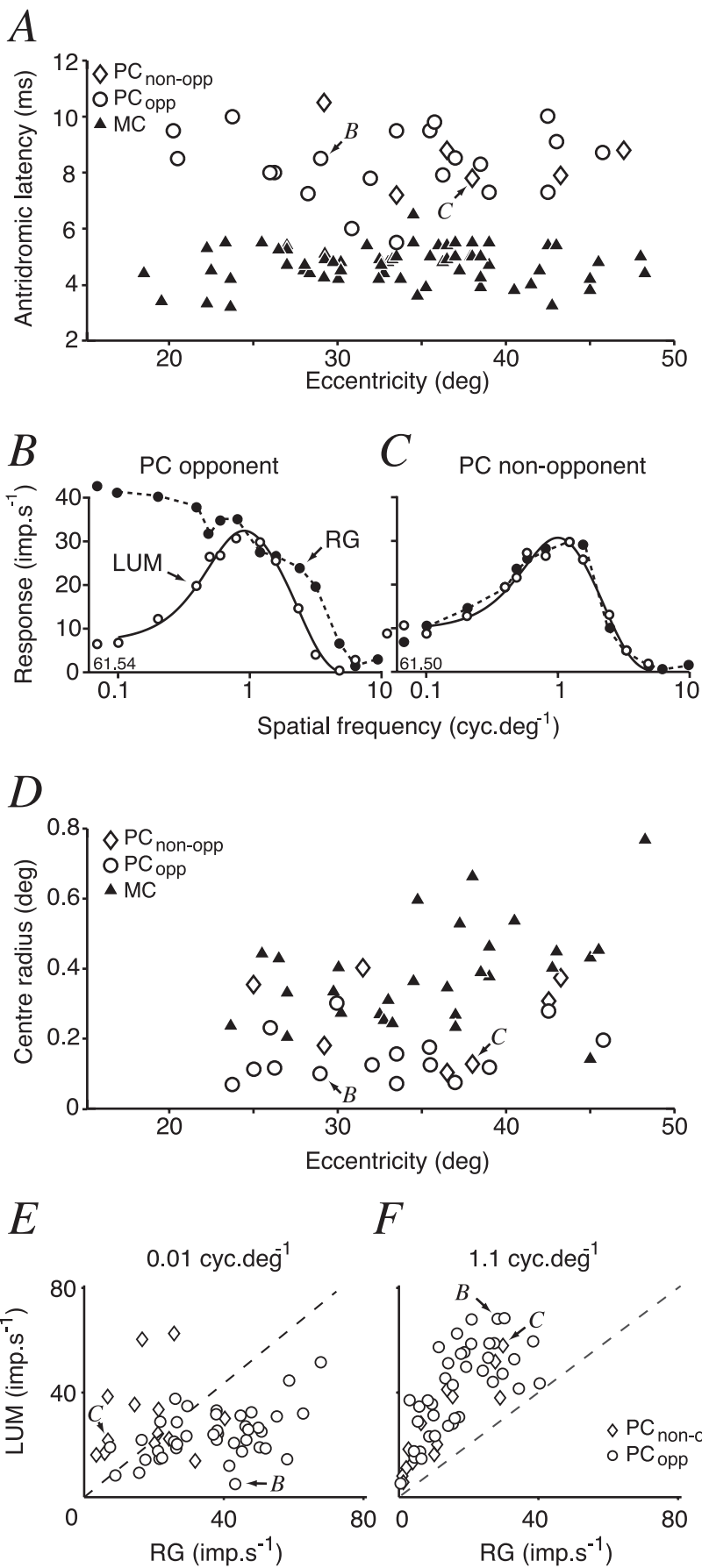

$F$

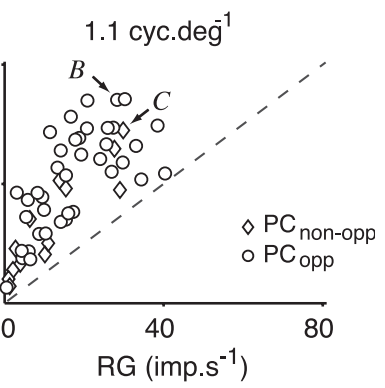

Figure 2. Identification and spatial properties of peripheral PC cells. $A$, Antidromic activation latencies after optic chiasm stimulation. Latencies of $M C$ pathway cells are shorter than latencies of $\mathrm{PC}$ pathway opponent $\left(\mathrm{PC}_{\text {opp }}\right)$ or $\mathrm{PC}$ pathway non-opponent ( $\mathrm{PC}_{\text {non-opp }}$ ) cells. The cells illustrated in $\boldsymbol{B}$ and $\boldsymbol{C}$ are indicated (arrows). $\boldsymbol{B}$, Spatial frequency tuning curves for high-contrast RG chromatic (filled circles; contrast 100\%) and low-contrast yellow-black LUM (open circles; contrast $25 \%$ ) drifting gratings for an opponent $\mathrm{PC}$ cell. At low spatial frequencies, the cell is more responsive to $R G$ gratings than LUM gratings. The solid lines show the best-fitting DOG model for the luminance gratings. $C$, Same as $\boldsymbol{B}$ but for a non-opponent $P C$ cell. In this case, the responses are consistent with dominant $M$-cone input to center and surround. $\boldsymbol{D}$, Center radius derived from DOG model fits. The cells illustrated in $\boldsymbol{B}$ and $\boldsymbol{C}$ are indicated (arrows). $E, P C$ cell responses to RG and LUM gratings of low spatial frequency $(0.01$ cycles per degree). Contrast of the luminance gratings was $100 \%$. The great majority of opponent cells show a greater response to RG than LUM. $\boldsymbol{F}$, Same as $\boldsymbol{E}$ but for gratings of medium spatial frequency (1.1 cycles per degree). All cells show a greater response to LUM than to RG. cyc, Cycles; deg, degree(s); imp.s ${ }^{-1}$, impulses per second. 
transfer characteristic, and the chromatic response is low pass, consistent with spatial segregation of opponent cones to the receptive field center and surround. The non-opponent PC cell shown in Figure $2 C$, in contrast, shows bandpass modulation transfer characteristics for both stimulus conditions. Analysis of the temporal properties of cone inputs to this cell showed dominant input from the $\mathrm{M}$ cone to the receptive field (see Fig. $7 B$, arrow). The responses shown in Figure $2 C$ are thus consistent with the idea that both the excitatory and the inhibitory inputs to the receptive field are dominated by a single cone class.

Examples of opponent and non-opponent PC cells were encountered within the same eye, and, in four cases, a nonopponent PC cell was encountered sequential to, and within $1^{\circ}$ eccentricity of, an opponent PC cell. Furthermore, both opponent and non-opponent PC cells were encountered in the peripheral retina of all the animals tested, so it is unlikely that individual differences in chromatic phenotype could account for the pattern of results seen.

There is substantial overlap between $\mathrm{PC}$ and $\mathrm{MC}$ receptive field radius for luminance modulation in foveal retina (Derrington and Lennie, 1984; Crook et al., 1988; Croner and Kaplan, 1995), but in the eccentricity range studied here, PC-cell radii measured for luminance modulation were consistently smaller than those of MC cells (Fig. 2D). On average, the non-opponent PC cells show slightly larger receptive field center radii (mean \pm $\mathrm{SD}, 0.26 \pm 0.12^{\circ} ; n=7$ ) than opponent PC cells (mean $\pm \mathrm{SD}$, $0.15 \pm 0.07^{\circ} ; n=15 ; p=0.02$; Wilcoxon's rank-sum test), but there was no clear correlation between receptive field radius and strength of opponent response (Fig. 2, compare B-D). As reported by others (Kaplan and Shapley, 1982; White et al., 2002), linearity of spatial summation was similar for PC cells (mean \pm SD NLI, $0.39 \pm 0.16 ; n=15$ ) and MC cells (mean \pm SD NLI, $0.43 \pm 0.25 ; n=20$ ) and well below the non-linearity criterion $(\mathrm{NLI}>1)$ for Y cells in cat retina (Hochstein and Shapley, 1976; White et al., 2002).

Chromatic opponency in peripheral PC cells was most strongly expressed at low spatial frequencies. In Figure 2, $E$ and $F$, the response amplitude for high-contrast (100\%) RG modulation is plotted against response amplitude for high-contrast (100\%) LUM modulation. Responses of the cells illustrated in Figure 2, $B$ and $C$, are indicated. Cells were classified as opponent or non-opponent using the LED stimulator as described below (Chromatic-temporal interaction in PC cells). Consistently, when tested using the CRT stimulator, nearly all of the opponent PC cells show more vigorous responses to red-green gratings than to high-contrast luminance gratings at 0.01 cycles per degree (mean \pm SD RG/LUM ratio, $1.50 \pm 1.56 ; n=31$ ) (Fig. $2 E$ ). The presence of a small number of cells that lie on the "wrong" side of the $1: 1$ line is not surprising given that stimulus conditions such as time-average luminance, field size, and chromatic purity differ between the LED stimulator and the CRT stimulator. The $\mathrm{M}$ - and L-cone contrasts produced by the chromatic grating $(\sim 28$ and $\sim 12 \%$, respectively) are less than one-third of those produced by the luminance grating. These data therefore provide strong evidence that antagonistic (opponent) interaction between $\mathrm{M}$ and $\mathrm{L}$ cones is present in the majority of PC cells.

When tested with a spatial frequency close to optimal (Fig. $2 F)$, nearly all PC cells are more responsive to luminance modulation than to red-green modulation (mean \pm SD RG/LUM ratio, $0.37 \pm 0.20 ; n=31 ; p<0.01$; Wilcoxon's paired-rank test). This is consistent with the idea that the receptive field surround mechanism contributes to the opponent response at low spatial frequencies. The broad spread of PC-cell responsivity to both luminance and chromatic modulation (Fig. 2E) suggest that PC cells in peripheral retina, like those in foveal retina (Derrington et al., 1984; Lee et al., 1987), form a single functional population with a variable degree of cone opponency.

The main purpose of our study was to compare the chromatic-temporal properties of ganglion cells in foveal and peripheral retina. We did not make extensive measurements using the CRT stimulator because it offered a limited gamut of intensity, spectral specificity, and temporal-stimulation bandwidth compared with the LED stimulator. Furthermore, interpretation of responses to chromatic gratings at high spatial frequencies is rendered difficult by the effects of chromatic aberrations in the medium-long wavelength range, which can introduce luminance contrast into ostensibly isoluminant stimuli (Thibos, 1987; Flitcroft, 1989; Anderson et al., 1991; Blessing et al., 2004). Thus, for example, both opponent interactions and/or luminance artifacts (attributable to chromatic aberrations) could contribute to the highfrequency limb of the red-green response curves in Figure 2, $B$ and $C$. With these reservations, it is worth noting that the spatial pattern of response in Figure $2 C$ was seen in other non-opponent PC cells and was usually consistent with dominant input from one ( $\mathrm{M}$ or $\mathrm{L}$ ) cone class to both center and surround of the receptive field.

Having established that a low stimulus spatial frequency is appropriate to measure red-green opponent interactions in PC cells, in the next section, we use temporal modulation of uniform spatial fields to show that the red-green opponent responses arise from interaction between temporally delayed opponent inputs to the receptive field.

\section{Chromatic-temporal interaction in PC cells}

Smith et al. (1992) found that changing the relative phase of modulation of red and green stimuli was a useful tool for investigating $\mathrm{M}$-cone and L-cone interactions. We measured such phase-dependent temporal responsivity in 36 peripheral PC cells. Responses of a cone-opponent (green-off) cell are shown in Figure 3. At low temporal frequency, cell responsivity was greatest for out-of phase (chromatic) modulation of the LEDs, but, with increasing temporal frequency, the phase of the response maximum moved and, at $40 \mathrm{~Hz}$, the cell showed greatest responsivity to in-phase modulation. This response pattern is characteristic of PC cells with M-cone centers in foveal retina and LGN (Smith et al., 1992; Lankheet et al., 1998). The majority of PC cells in peripheral retina showed either this pattern of response (green-on, $n=3$; green-off, $n=8$ ) or the opposite pattern of frequencydependent phase shift, consistent with L-cone centers (red-on, $n=14$; red-off, $n=2$ ). The remaining cells were classified as "tonic non-opponent on" $(n=5)$ or "tonic non-opponent off" $(n=2)$ using criteria described below.

All PC cells showed a variable degree of harmonic response distortion. This was manifest in non-opponent PC cells as a frequency-doubled response for out-of-phase LED modulation. An extreme example is shown in Figure 4 (right panel). We quantified response distortion by averaging the second-harmonic response amplitude over all relative LED phases and dividing this number by the maximum value of the first-harmonic response (nonlinearity index). For example, the nonlinearity indices for the cells shown in Figures 3 and 4 were 0.33 and 0.42, respectively. The nonlinearity index for non-opponent PC cells (mean \pm SD, $0.38 \pm 0.19 ; n=6$ ) showed substantial overlap with that for peripheral opponent PC cells (mean $\pm \mathrm{SD}, 0.31 \pm 0.10$; $n=25$; $p=0.38$; Wilcoxon's rank-sum test), suggesting that the phe- 
nomenon is not uniquely associated with non-opponent PC cells. We have not investigated this effect further.

In foveal PC cells, responsivity to redgreen modulation depends on the temporal frequency of stimulation. This is because the delay between receptive field center and surround represents a phase lag great enough to cancel these cone opponent inputs to the cell at high temporal frequencies (Gouras and Zrenner, 1979; Smith et al., 1992; Lankheet et al., 1998). We asked whether the same mechanism could explain the behavior of opponent $\mathrm{PC}$ cells in peripheral retina. We fit data from the phase paradigm with the linear vector model developed by Smith et al. (1992) as described above (see Materials and Methods). Figure 5 shows amplitude and phase data for a red-on center cell (Fig. $5 A$ ) and a green-on center cell (Fig. 5B), together with model fits (solid lines). For all of the opponent PC cells, the model provided a satisfactory account of response amplitude and phase, consistent with a phase delay of 5-15 ms between the opponent cone inputs to the receptive field. This paradigm provides a robust test for opponent combination of $\mathrm{M}$ - and L-cone inputs, which is indicated if the response minimum lies between $-90^{\circ}$ and $+90^{\circ}$ relative LED phase (that is, the stimulus range at $\mathrm{M}$ - and L-cone inputs to the cell have the same sign).

Responsivity minima of peripheral opponent PC cells, plotted as a function of temporal frequency, are shown in Figure 6. The temporal-frequency dependency was similar to that of their counterparts in foveal retina (Fig. 6) (Smith et al., 1992), which is consistent with the idea that the opponent properties originate in center-surround interactions. In contrast, the non-opponent PC cells showed response minima outside the range of $\pm 90^{\circ}$ for all temporal frequencies tested.

The distribution of $\mathrm{M} / \mathrm{L}$-cone weight and response phase minima for $1.22 \mathrm{~Hz}$ modulation are shown in Figure 7. We used the position of the response phase minimum as the basis for classifying PC cells as opponent or non-opponent (Fig. $7 A, B$, gray bars). There was little difference in the mean L/M-cone weight between foveal (mean, $0.34 ; n=19$ ) and peripheral (mean, $0.36 ; n=35$ ) PC cells ( $p=0.85$; Wilcoxon's rank-sum test). The peripheral PC cells showed greater variability in $\mathrm{M} / \mathrm{L}-$ cone weight (SD, 0.10) than did cells in foveal retina (SD, 0.03). Furthermore, as can be seen in Figure 7, comparing $A$ with $B$, the response phase minima at $1.22 \mathrm{~Hz}$ were also more variable in peripheral (mean $\pm \mathrm{SD}, 14.3 \pm 63.1^{\circ} ; n=35$ ) than in foveal PC cells (mean $\pm \mathrm{SD}, 1.7 \pm 14.6 ; n=19$ ). These observations are consistent with a reduced degree of functional segregation of the cone inputs to the receptive field of peripheral PC cells, a possibility that we explored using the linear model of temporalcontrast sensitivity described in the next section.

With increasing temporal frequency, the proportion of PC cells showing an opponent response signature became progressively smaller. As shown in Figure $7 C$, this change from opponent to non-opponent response signature occurs at lower temporal frequencies in peripheral than in foveal retina. In the following section, we show that systematic changes in the center-surround delay and temporal filtering of cone inputs can account for these eccentricity-dependent changes.
PC non-opponent

$2.44 \mathrm{~Hz} \quad 9.76 \mathrm{~Hz}$

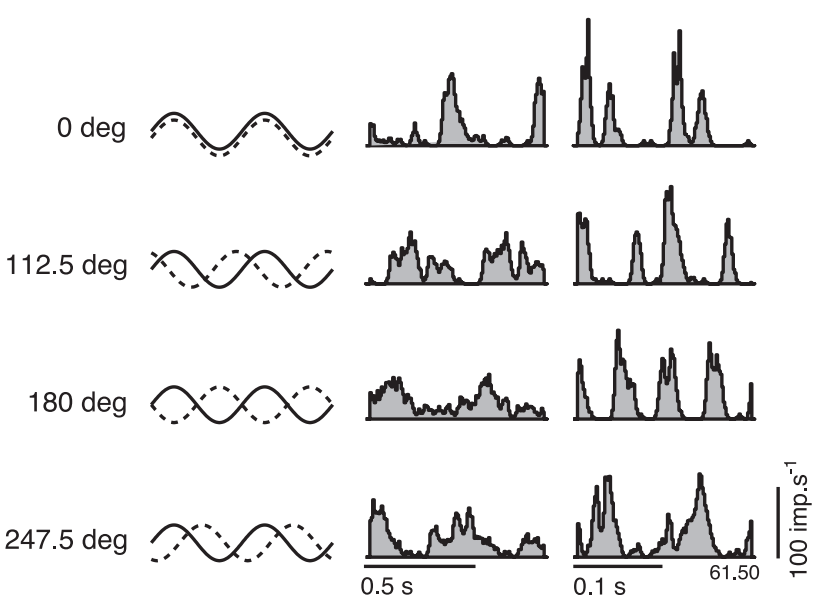

Figure 4. Response of a non-opponent PC cell to temporal modulation of red and green LEDs. The PSTHs are shown for two temporal frequencies at each of four relative LED phases. The stimulus waveform is sketched in the left panel. Modulation frequency is shown above each column of histograms. The response minimum is close to $180^{\circ}$ at low frequency. This cell shows a frequency-doubled response at $9.76 \mathrm{~Hz}$ (right panel). The receptive field eccentricity of this cell was $38^{\circ}$; its spatial frequency tuning curve is shown in Figure $2 C$. deg, Degrees; imp. $s^{-1}$, impulses per second.

\section{Analysis of PC-cell responses to chromatic and luminance contrast}

Our observation of opponent responses in peripheral PC cells at first sight appears at odds with the recent observations of Diller et al. (2004), who reported almost exclusively non-opponent combination of M- and L-cone inputs to PC cells in peripheral retina. We next developed and used a linear model of temporalfrequency-dependent chromatic sensitivity to show how this apparent discrepancy can be resolved.

Building on the successful analysis of responses to the phase paradigm, we developed a linear filter model (described in Materials and Methods), which assumes that a PC-cell receptive field comprises antagonistic center and surround mechanisms with the same temporal-filtering characteristics but different spectral tuning.

We obtained both chromatic and luminance transfer func- 


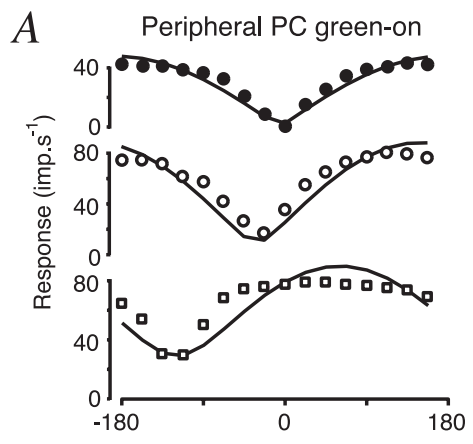

$B$ Peripheral PC red-on
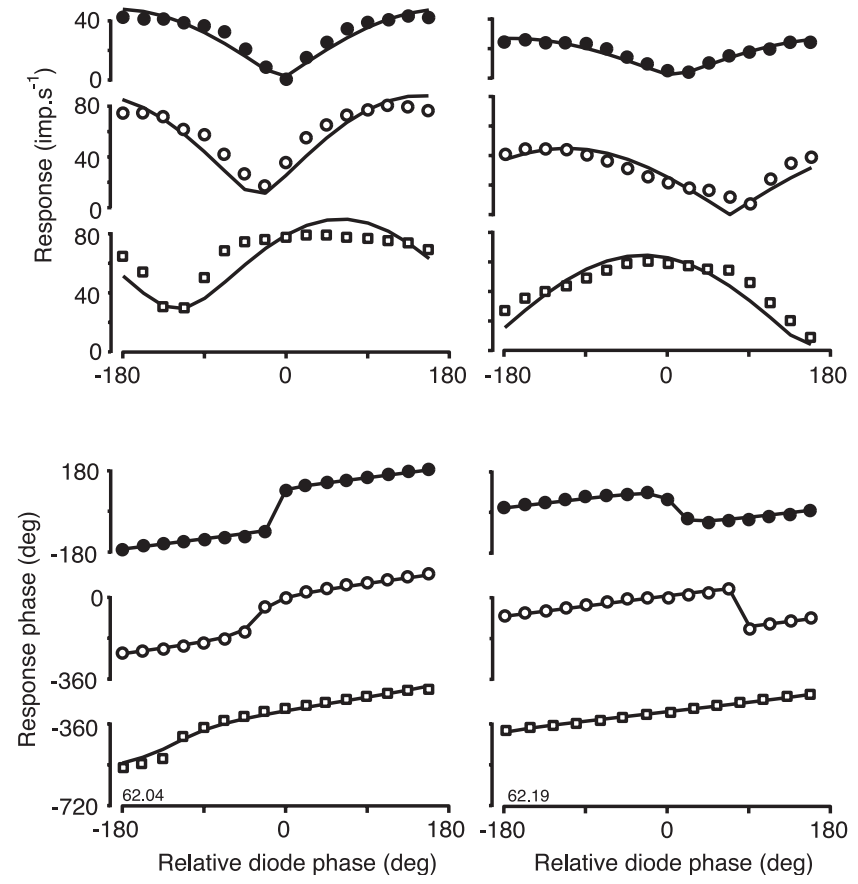

Figure 5. First-harmonic amplitude and phase response plots for two peripheral opponent PC cells. Responses are shown as a function of the relative phase of the green LED for each of three temporal frequencies. $\boldsymbol{A}$, Green-on cell, receptive field eccentricity $25^{\circ}$. $\boldsymbol{B}$, Red-on cell, eccentricity $30^{\circ}$. Filled circles, $1.22 \mathrm{~Hz}$; open circles, $9.76 \mathrm{~Hz}$; open squares, $39.04 \mathrm{~Hz}$. The phase of minimum sensitivity (the green LED phase at the response minimum) shifts toward $0^{\circ}$ at high temporal frequencies. In this and subsequent figures, response phase is expressed relative to the zero transition of the red LED. deg, Degrees; imp.s ${ }^{-1}$, impulses per second.

tions for 29 opponent PC cells. Responses of a peripheral red-on cell (receptive field eccentricity, $25^{\circ}$ ) are shown in Figure 8 together with model fits. Both responses and model predictions are shown as Bode plots, which plot separately the response gain and phase of the transfer function. The model accounts for most aspects of the response of the cell to both chromatic and luminance stimulation. Note that, for this red-on cell, the inhibitory input from $\mathrm{M}$ cones dominates the response of the cell to chromatic modulation, because the M-cone contrast generated by the LED stimulator $(\sim 68 \%)$ was greater than the L-cone contrast $(\sim 20 \%)$. The phase of the response of the cell thus primarily follows that of the $\mathrm{M}$ cone for chromatic stimulation, but, at high temporal frequencies, the response phase of center and surround diverges because of the additional surround delay.

For luminance modulation, the center and surround are antagonistic at low temporal frequencies, and the phase of cell response follows that of the center. At higher temporal frequencies, the additional phase delay of the surround causes the center and surround response phase to converge. We conclude that the model gives a reasonable account of the response of this cell to both luminance and chromatic-temporal modulation.

\section{Eccentricity-related changes in temporal responsivity of PC cells}

Fits of similar quality to those shown in Figure 8 were obtained for the great majority of cells in our sample. We therefore asked whether the linear model could help to explain the eccentricitydependent changes in the response properties of PC cells.

As a first step, we fit the linear filter model to average cell responses. The most common opponent PC cells in our sample
$A$

Foveal
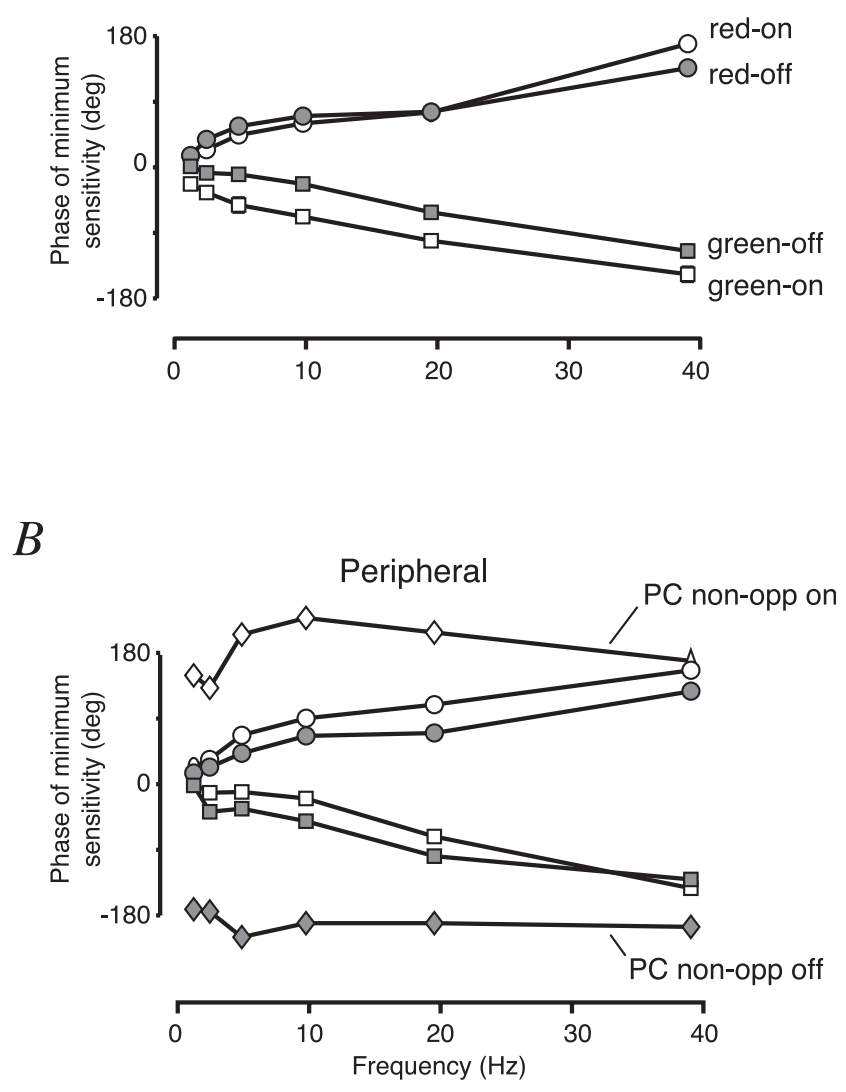

Figure 6. Phase of minimum sensitivity as a function of temporal frequency. $\boldsymbol{A}$, Foveal cells. $\boldsymbol{B}$, Peripheral cells. One example of each of the red-green opponent classes is shown; note that the direction of phase shift depends on whether the cell receives excitatory input from $\mathrm{M}$ or $\mathrm{L}$ cones. For opponent cells in the fovea and periphery, the phase of minimum response is close to $0^{\circ}$ at low temporal frequencies. For non-opponent cells recorded in peripheral retina, the phase of minimum response is outside the range of -90 to $+90^{\circ}$ at all frequencies tested. $P C_{\text {non-opp }}$ on, $P C$ pathway non-opponent on-cells; $P C_{\text {non-opp off }} P$ P pathway non-opponent off-cells. deg, Degrees.

were red-on cells (17 of 29, 59\%). Figure 9, $A$ and $B$, shows, in the same format as Figure 8, the average chromatic and luminance transfer functions for red-on cells in the three eccentricity groups, as well as the best-fitting solutions of the linear filter model. The fits are satisfactory, with the exception that responses to low-frequency luminance modulation are underestimated for peripheral cells (Fig. 9A, right panel). Figure 9C shows the MSE for each of the 24 data points in the complex plane when all parameters were allowed to vary except for the surround cone weighting (L/M ratio, $W$ ). The best-fitting values of $W$, which were used to generate the smooth curves in Figure 9, $A$ and $B$, are indicated. As observed previously (Smith et al., 1992; Lankheet et al., 1998; Lee et al., 1998), for foveal PC cells, responses are best predicted by a "pure opponent" surround, but the error function is very shallow. Thus, the model cannot reliably distinguish some admixture of non-opponent cones in the surround. For red-on cells between $20^{\circ}$ and $30^{\circ}$ eccentricity, the error function is likewise shallow but shows a minimum at $W \sim 0.3$. This nonopponent (L-cone) input to the surround is manifest in the gain plots (Fig. 9A, middle) in which the sensitivity to high-frequency luminance modulation exceeds the maximum sensitivity to chromatic modulation. For red-on cells at eccentricities above $30^{\circ}$, the error function shows a clear minimum at $W \sim 0.5$; this is reflected 
$A$

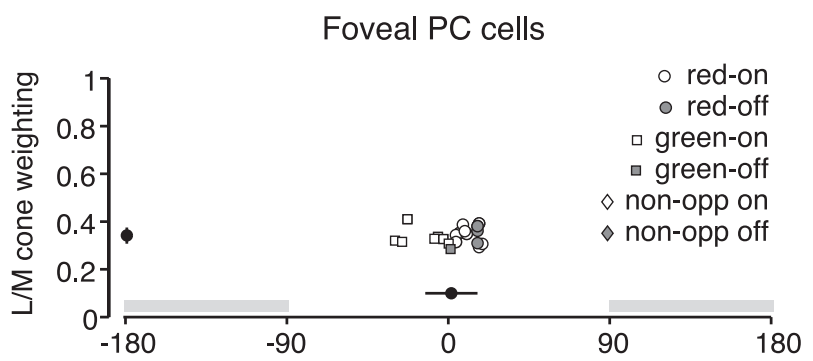

$B$

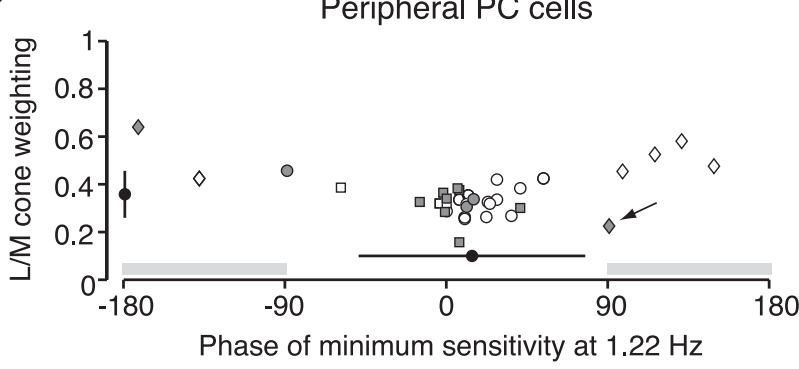

C

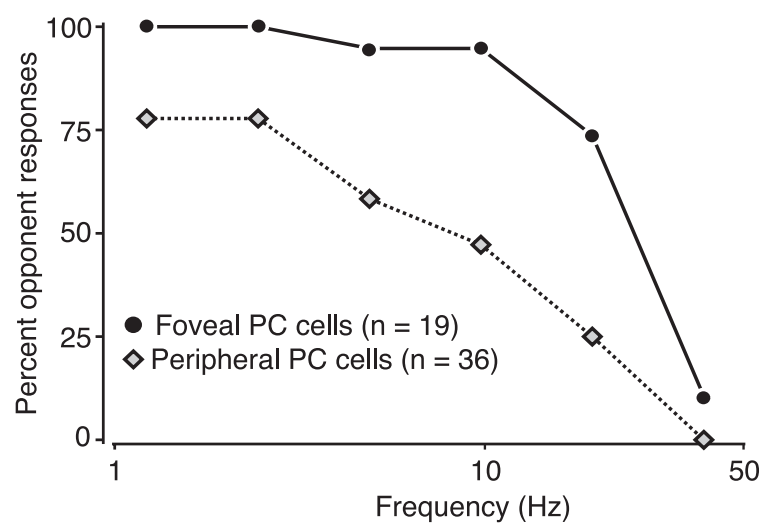

Figure 7. Characteristics of opponent responses in foveal and peripheral PC cells. Each graph shows the phase of minimum sensitivity and the relative cone weight for all $P C$ cells. Foveal cells (A) show lower variability in the phase of minimum response and relative strength of cone inputs than peripheral cells $(\boldsymbol{B})$. The filled circles and lines near the axes in $\boldsymbol{A}$ and $\boldsymbol{B}$ give the mean and SD of all PC cells shown. The gray bars near the abscissa show the range of green LED phase within which a sensitivity minimum indicates a non-opponent combination of $M$ and $L$ cones. The non-opponent cell illustrated in Figure $2 \mathrm{C}$ is indicated with an arrow. Note the strong M-cone weight to this cell. C, Proportion of $\mathrm{PC}$ cells showing opponent response signature as a function of temporal frequency. non-opp on, Non-opponent on-cells; non-opp off, nonopponent off-cells.

in the gain plots by very high sensitivity to high-frequency luminance modulation and a reduced sensitivity to chromatic modulation. These data suggest that the surround mechanism for peripheral PC cells does not show cone selectivity.

Compared with PC cells in foveal retina, for peripheral cells the model consistently returned (1) lower values for the time constant of the low-pass filter and (2) larger center-surround delay values. These changes are manifest in the gain and phase plots in two ways.

First, the peripheral PC cells show greater sensitivity and relative phase advance for both chromatic and luminance modulation at high temporal frequencies (Fig. $9 A, B$ ). These features are compatible with a reduction of the time constant of the low-pass
$A$

Peripheral PC red-ON cell
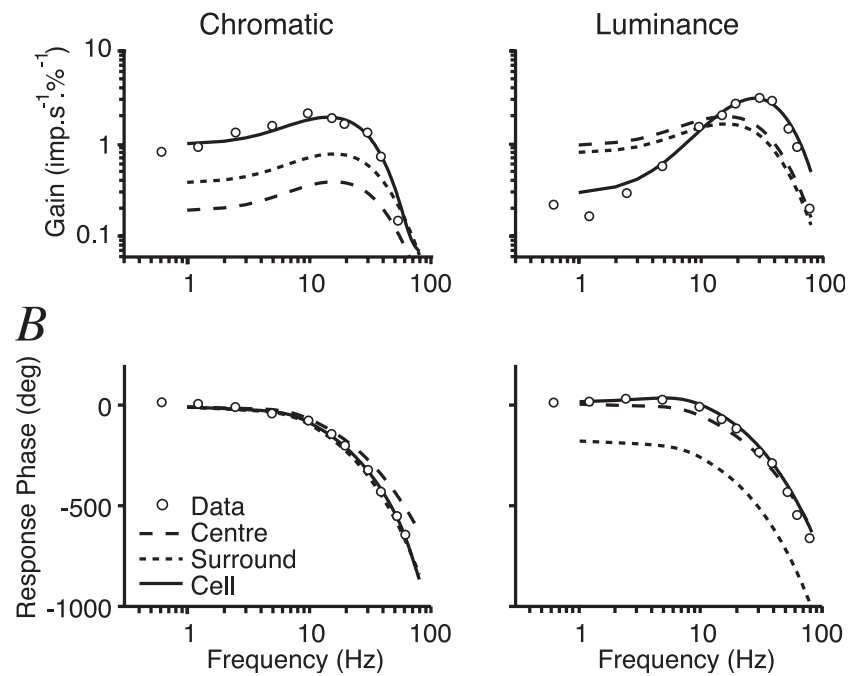

Figure 8. Luminance and chromatic transfer functions of a peripheral red-on PC cell. $A$, Gain for chromatic and luminance contrast. Contrast gain was calculated as the initial slope of a Naka-Rushton function fit to contrast-response functions obtained at each temporal frequen$c y$; contrast is the modulation depth of the LEDs. $\boldsymbol{B}$, Response phase for these stimuli. Response phase at each frequency was obtained from the lowest contrast that generated a response amplitude $>10$ impulses per second (imp. $\mathrm{s}^{-1}$ ). Smooth lines in $\boldsymbol{A}$ and $\boldsymbol{B}$ show best-fit solutions of the linear filter model described in Materials and Methods and illustrated in Figure 1. The frequency response of center and surround components of the receptive field (dashed lines) was generated from these fits. The receptive field eccentricity of this cell was $26^{\circ}$. deg, Degrees.

filter, which also allows the resonance (second-order) filters to become more important in the responses of peripheral cells. The second-order filter is thus a dominant contributor to the sharp high-frequency peak in luminance sensitivity.

Second, the PC population shows a progressive, eccentricitydependent reduction in the range of temporal frequencies over which response gain for chromatic modulation exceeds the gain for luminance modulation (Fig. 9A). This arises both because of the sharp increase in luminance sensitivity described above and because of increased center-surround delay. The increased delay serves to reduce the range of (low) frequencies for which the surround and center are activated synergistically by chromatic modulation but activated antagonistically for luminance modulation.

The fit parameters for the other opponent PC cells in our sample were consistent with the data from red-on cells, although there was substantial inter-cell variability. The time constant of the low-pass filter cascade, and the surround delay, are shown as functions of eccentricity in Figure 10. The mean time constant for PC cells within $15^{\circ}$ of the fovea (mean \pm SD, $2.42 \pm 1.35 \mathrm{~ms} ; n=$ 13 ) is greater than that of peripheral PC cells (mean \pm SD, $1.02 \pm$ $0.56 \mathrm{~ms} ; n=16 ; p=0.016$; Wilcoxon's rank-sum test). The center-surround delay shows an eccentricity-dependent increase (Fig. $10 \mathrm{~B}$ ), with mean value for foveal cells (mean \pm SD, $2.80 \pm 3.67 \mathrm{~ms} ; n=13$ ) approximately half that of peripheral cells (mean \pm SD, $6.45 \pm 3.68 \mathrm{~ms} ; n=16$ ). We conclude that the eccentricity-dependent changes in contrast sensitivity of PC cells can primarily be accounted for by changes in two key parameters: the temporal-filtering properties of pre-ganglion cell synaptic circuits and the delay between center and surround.

\section{Chromatic input to peripheral MC cells}

If the retinal circuits that generate $\mathrm{M} / \mathrm{L}$-cone opponency are maintained in peripheral retina, then it might be expected that 


\section{$\mathrm{PC}$ red-on cells}
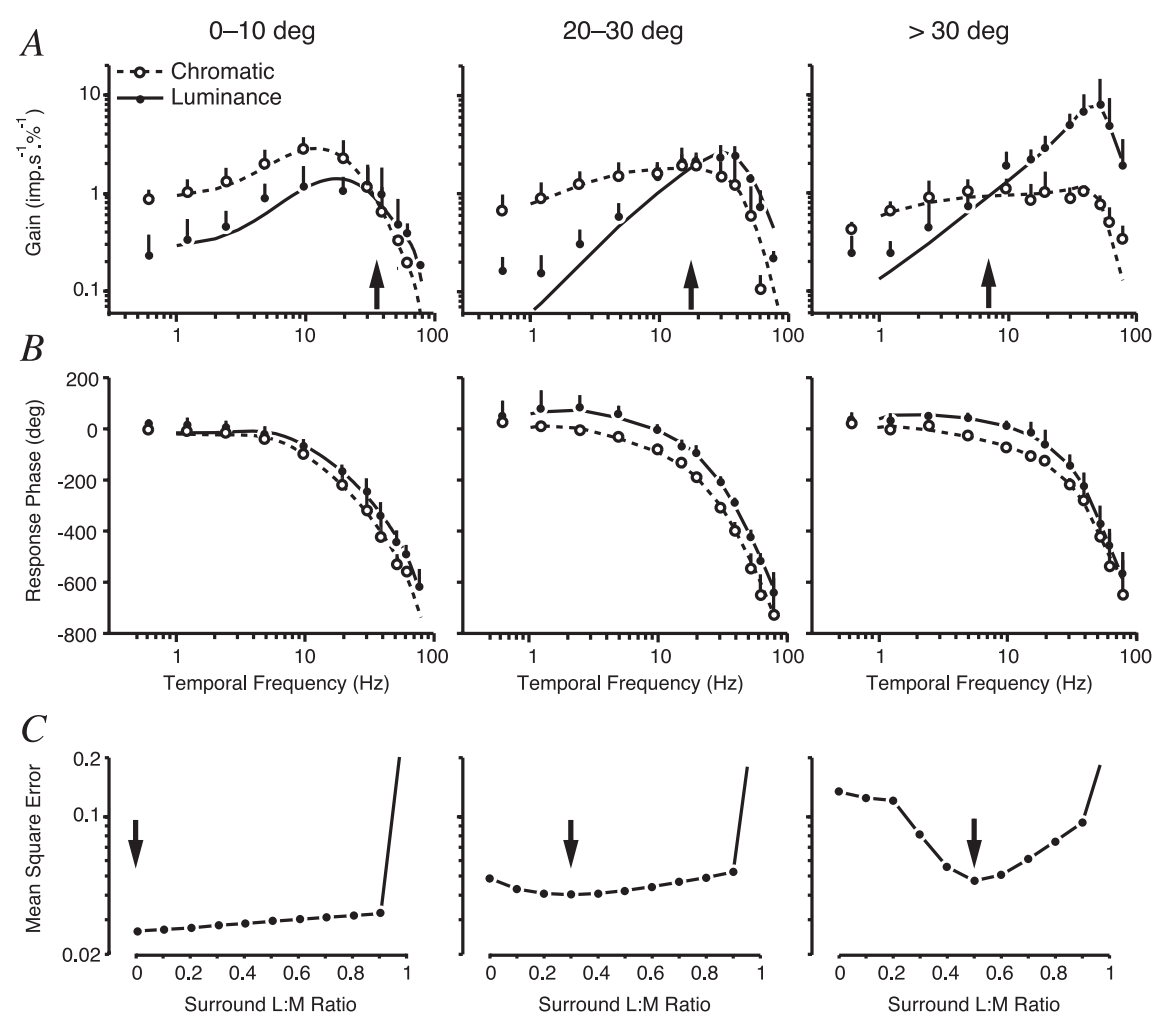

Figure 9. Eccentricity-dependent changes in luminance and chromatic transfer functions of red-on cells. $A, B$, Average contrast gain $(\boldsymbol{A})$ and response phase $(\boldsymbol{B})$ for red-on cells in three eccentricity ranges. Error bars show 1 SEM. Note the sharp increase in sensitivity to high-frequency luminance modulation with increasing eccentricity. Arrows in $\boldsymbol{A}$ indicate the crossover frequency for the luminance and chromatic contrast sensitivity functions. $C$, Residual error functions. The linear model was fit to responses shown in $\boldsymbol{A}$ and $\boldsymbol{B}$, with the relative weight of $\mathrm{L}$ and $\mathrm{M}$ cones in the receptive field surround fixed at 1 of 11 values shown. The smooth lines in $\boldsymbol{A}$ and $\boldsymbol{B}$ show solutions of the linear filter model, obtained using the ratio that yielded the minimum residual error, as indicated by the arrows in $\mathbf{C}$. deg, Degrees; imp. ${ }^{-1}$, impulses per second.

the weak chromatic input to MC cells would also be manifest. We found this to be the case. Responses of an on-center MC cell to the phase paradigm are shown in Figure $11 \mathrm{~A}$. At $1.22 \mathrm{~Hz}$, the minimum response occurs at close to $30^{\circ}$. With increasing frequency, the minimum response moves toward $\pm 180^{\circ}$ (chromatic modulation). This pattern of response is very similar to that of foveal MC cells (Fig. 11B) (Smith et al., 1992, their Fig. 7). The solid lines in the amplitude plots are the fits of a cosine function, which provided an estimate of the LED phase of minimum response. This variable is plotted as a function of temporal frequency for on-center $(n=17)$ and off-center $(n=10)$ MC cells in Figure $11 B$, together with the data for foveal MC cells from Smith et al. (1992). The foveal and peripheral results show a similar pattern, suggesting that a similar underlying mechanism, i.e., a chromatic input, is present. As in foveal retina, these phase shifts were absent when the stimulus was restricted to the receptive field center (data not shown).

Analysis of these phase-dependent changes in foveal retina had shown that they could only be accounted for by an opponent signal in the receptive field surround (Smith et al., 1992). The data in Figure 11 show that the same kind of behavior is a feature of MC cells in peripheral retina, and we suggest that it arises from the same chromatic interactions in pre-ganglion cell synaptic circuitry.

At moderate to high temporal frequen-

$A$

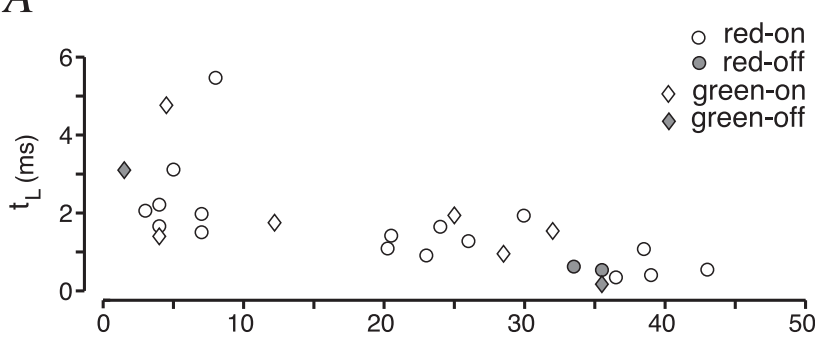

\section{$B$}

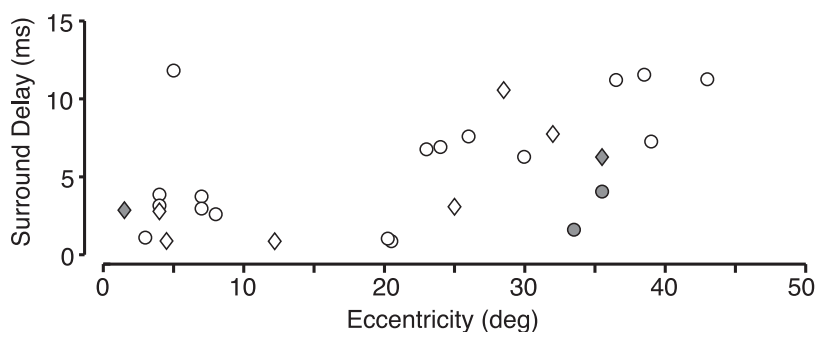

Figure 10. Eccentricity-dependent variation of linear filter model parameters. $\boldsymbol{A}$, Low-pass filter cascade time constant $\left(t_{L}\right)$ shows a systematic decrease with increasing eccentricity. $\boldsymbol{B}$, Surround delay shows an increase with increasing eccentricity. deg, Degrees. cies, MC cells in foveal retina give a response at twice the modulation frequency with full-field chromatic modulation (Lee et al., 1989). We found this also to be a feature of MC responses in peripheral retina. The histograms in Figure $12 \mathrm{~A}$ show responses of an off-center MC cell to two cycles of modulation. One histogram shows the response to luminance modulation with the 638 $\mathrm{nm}$ (red) and $554 \mathrm{~nm}$ (green) LEDs modulated in-phase. The other histogram shows responses with the LEDs modulated in counter phase. A frequency-doubled response is apparent. The amplitude of first- and second-harmonic response are plotted against 554/638 nm ratio in Figure $12 \mathrm{~B}$. The first harmonic goes through a minimum close to a ratio of unity, i.e., chromatic modulation. Second-harmonic amplitude rises to a maximum at this point. The arrows indicate the modulation ratios at which, based on the Smith-Pokorny fundamentals (Smith and Pokorny, 1975), either the M or the L cone are not modulated. Outside this range, the $\mathrm{M}$ and $\mathrm{L}$ cones are modulated in-phase, and, within it, they are modulated in counter phase. There is pronounced second-harmonic distortion, both within and outside the silent substitution ratios. As shown previously for foveal MC cells, this behavior would not be expected on the basis of simple nonlinear summation of M and L cones (Lee et al., 1993) and may be attributable to a rectified chromatic signal in the MC receptive field surround (Lee and Sun, 2003). Figure 12C shows first- and second-harmonic amplitudes with a $1^{\circ}$ stimulus field. The frequency-doubled response is greatly diminished if the stimulus 

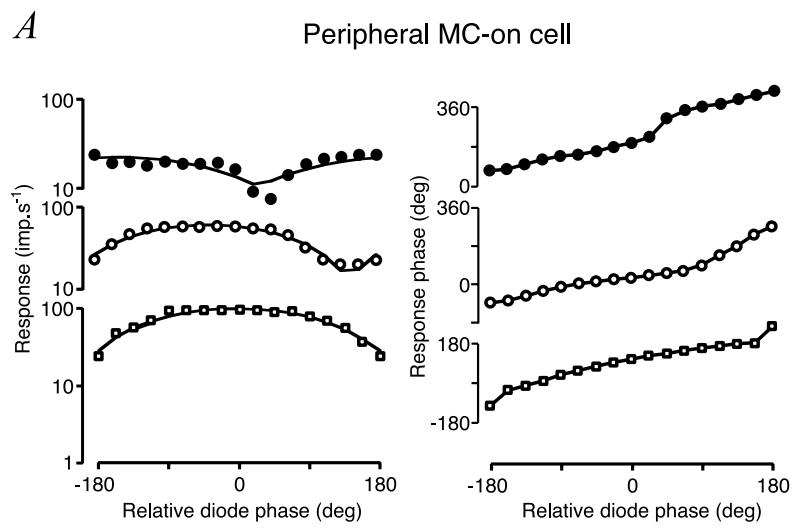

$B$

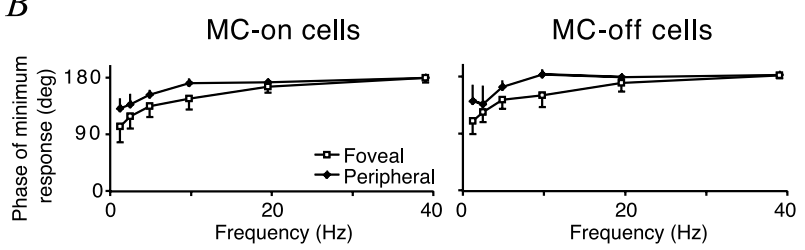

Figure 11. Chromatic response properties of MC pathway cells. $A$, Responses of one MC cell to the phase paradigm. Filled circles, $1.22 \mathrm{~Hz}$; open circles, $9.76 \mathrm{~Hz}$; open squares, $39.04 \mathrm{~Hz}$. Response phase is the sine relative to the zero transition of the red LED. Note the response minimum for luminance (in-phase) LED modulation at $1.22 \mathrm{~Hz} . \boldsymbol{B}$, Mean values for MC cells ( \pm 1 SEM) compared in foveal and peripheral retina. Note that the phase of minimum amplitude shift is in the same direction for on- and off-type MC cells and that foveal and peripheral cells exhibit similar behavior. deg, Degrees; imp.s ${ }^{-1}$, impulses per second.

is substantially restricted to the receptive field center. Similar results were also found with 27 other MC cells studied with this protocol.

In summary, these data show that features of MC-cell responses, which can be attributed to the activity of chromatic mechanisms, are also present in peripheral retina.

\section{Responses of blue-on cells}

The blue-on cells characteristically gave a vigorous, sustained excitatory response to short-wavelength light but were inhibited by longer wavelengths. The mean antidromic activation latency (mean $\pm \mathrm{SD}, 7.9 \pm 1.7 \mathrm{~ms} ; n=14$ ) was close to that of PC cells. The average frequency responses of foveal $\left(<15^{\circ}\right)$ and peripheral blue-on cells are shown in Fig. 13. For both the S-cone isolating stimulus and the silent-S (M+L-cone isolating) stimulus, the frequency of peak sensitivity is close to $20 \mathrm{~Hz}$, with some lowfrequency attenuation. Compared with foveal blue-on cells (Yeh et al., 1995a), peripheral blue-on cells were slightly less sensitive to modulation frequencies below $10 \mathrm{~Hz}$ and slightly more sensitive to higher modulation frequencies. This pattern of eccentricity-dependent changes is the same as outlined above for PC cells, suggesting increasing transience of inputs to blue-on cells with increasing eccentricity.

Blue-on cells give excitatory responses to increasing S-cone activation (blue-on) and a yellow-off response to decreasing $(\mathrm{M}+\mathrm{L})$-cone activation (Zrenner and Gouras, 1981; Lee et al., 1987; Dacey and Lee, 1994). In foveal retina, the temporal phase of blue-on responses to uniform spatial modulation is opposite for S cone-isolating and silent-S stimuli (Yeh et al., 1995a). We asked whether this pattern of response was maintained in peripheral retina by measuring the response phase of peripheral blue-on cells to both S-cone isolating and silent-S stimuli. The response phase difference was not significantly different from $180^{\circ}$ for all

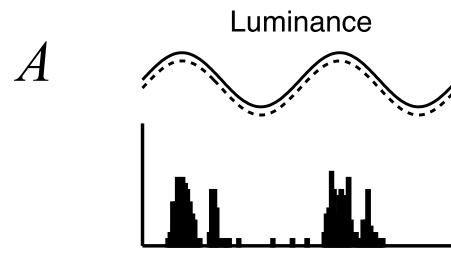

554/695 nm ratio: 1

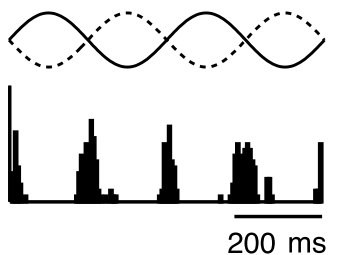

$B$

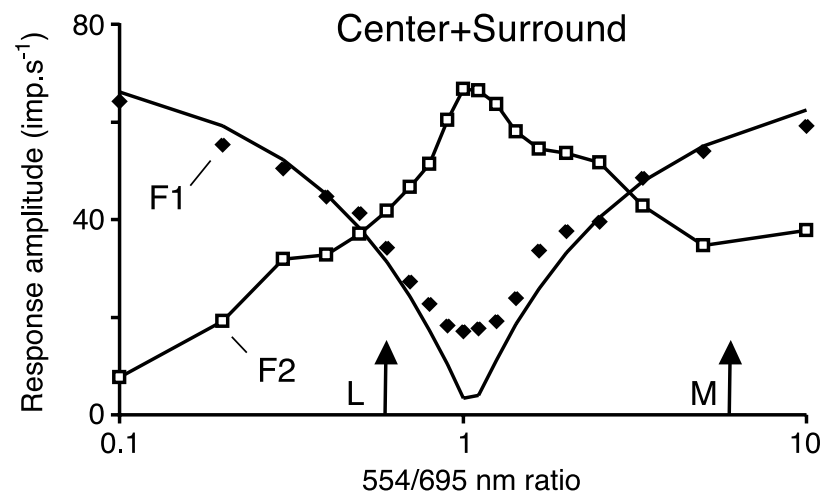

C

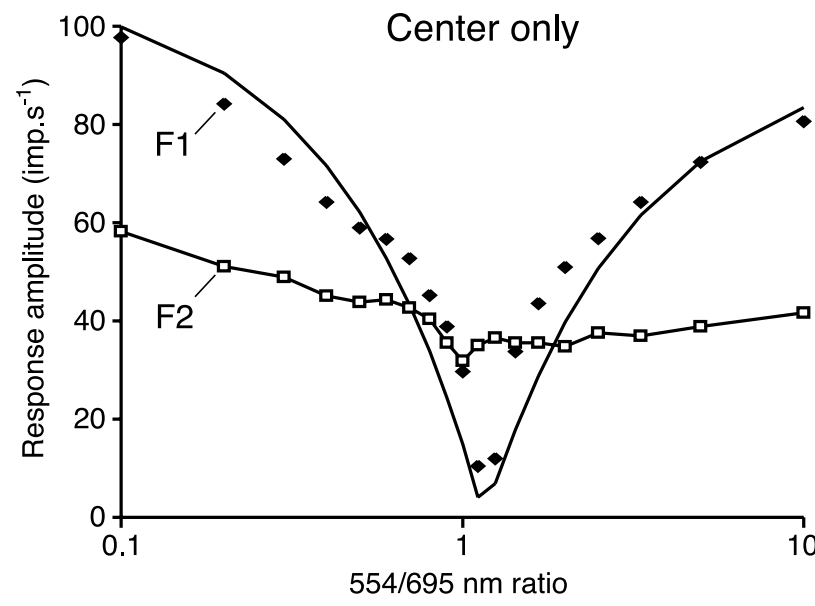

Figure 12. Nonlinear characteristic of MC cells for chromatic contrast. A, Example PSTHs, showing response to two cycles of LED modulation for luminance and chromatic (isoluminant) conditions. Note that frequency-doubled response distortions predominate at isoluminance (ratio 1). $\boldsymbol{B}$, Amplitude of first- and second-harmonic Fourier components as a function of $554 / 638$ ratio. Second-harmonic response is maximal at equal luminance, in which firstharmonic amplitude is minimal. Arrows indicate ratios predicted to give silent substitution for $\mathrm{L}$ - and M-cone mechanisms. C, Dependence of second harmonic response amplitude on modulation ratio is greatly diminished for a $1^{\circ}$ (center isolating) stimulus field, consistent with the nonlinearity arising in the receptive field surround. imp. $s^{-1}$, Impulses per second.

temporal frequencies tested ( $p>0.05$; one-sample test for mean angle), consistent with antagonistic inputs from $\mathrm{S}$ and $\mathrm{M}+\mathrm{L}$ cones (data not shown).

Blue-on cells are customarily described as possessing overlapping ("type 2") blue-on and yellow-off subregions, consistent with specialization for transmitting spectral difference signals (Wiesel and Hubel, 1966; Dreher et al., 1976). We measured spatial dimensions of 15 peripheral blue-on receptive fields. Drift velocity was $4.3 \mathrm{~Hz}$. Example responses are shown in Figure 14, A and $B$, together with difference-of-Gaussians fits. The radius of the $S$ region was moderately correlated with the radius of the $\mathrm{M}+\mathrm{L}$ region (correlation coefficient of 0.70 ). For the majority of 

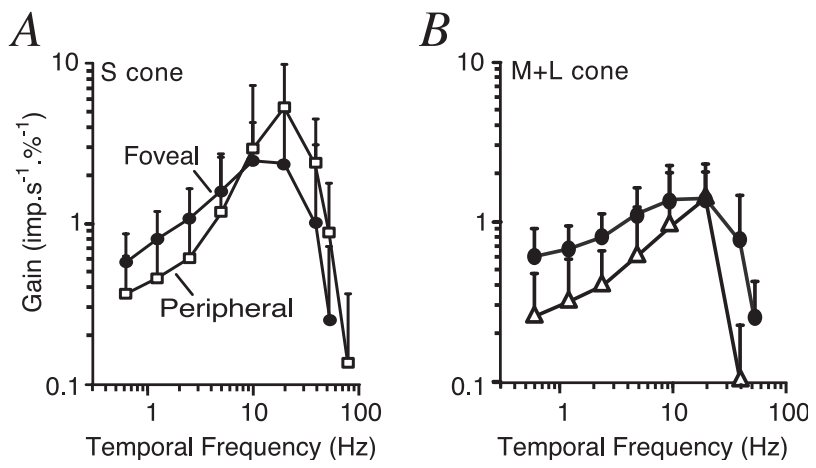

Figure 13. Frequency response of blue-on cells in peripheral retina. $\boldsymbol{A}$, Comparison of frequency response (contrast gain) for $S$-cone isolating modulation for foveal and peripheral cells. $\boldsymbol{B}$, Frequency response for stimuli (silent- $S$ ) that modulate only the $\mathrm{M}$ and $\mathrm{L}$ cones. For both S-cone isolating and silent-S modulation, the peripheral blue-on cells are, on average, slightly less sensitive to low temporal-frequency modulation. imp. $s^{-1}$, Impulses per second.
A

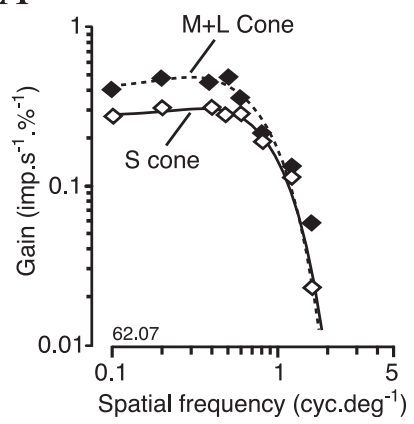

$B$

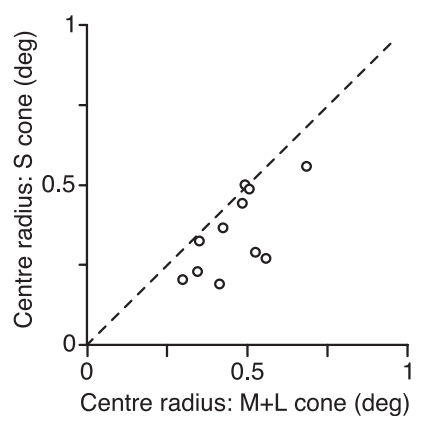

Figure 14. Spatial properties of peripheral blue-on cells. $A$, Example spatial frequency tuning curves for a peripheral blue-on cell (eccentricity $22^{\circ}$ ). Lines show DOG fits. Responses to both $S$-cone isolating and silent- $S$ gratings are predominantly spatial low pass. $\boldsymbol{B}$, Comparison of center radius measured with $S$-cone isolating and silent $S(M+L)$ gratings. Center radius was obtained from DOG fits as in $\boldsymbol{A}$ and $\boldsymbol{B}$. The $\mathrm{S}$-cone center mechanism is slightly smaller than the $\mathrm{M}+\mathrm{L}$ mechanism. cyc, Cycles; deg, degree(s); imp. $\mathrm{s}^{-1}$, impulses per second.

cells tested ( 10 of $11,91 \%$ ), the radius of the $S$ region (mean \pm $\mathrm{SD}, 0.35 \pm 0.13^{\circ}$ ) was smaller than the radius of the $\mathrm{M}+\mathrm{L}$ region (mean $\pm \mathrm{SD}, 0.46 \pm 0.11 ; p<0.01$; Wilcoxon's paired-rank test).

Our data suggest that spatial and temporal response properties of blue-on cells are preserved across the retina. These results are consistent with psychophysical evidence that there is only a mild decrease in S-cone-mediated sensitivity in peripheral retina (Mullen and Kingdom, 1996). Furthermore, the receptive field dimensions, as estimated from responses to drifting gratings, are broadly consistent with previous measurements of blue-on receptive fields in in vitro preparations of primate retina (Dacey and Lee, 1994; Chichilnisky and Baylor, 1999). Finally, the constant phase difference of $S$ and $M+L$ inputs to blue-on cells seen in the present study (Yeh et al., 1995a) is consistent with the finding of similar inferred response latency in S and $\mathrm{M}+\mathrm{L}$ inputs to blue-on cells (Chichilnisky and Baylor, 1999). Together, this is evidence that the retinal circuitry for blue-on chromatic selectivity is preserved at least to $40^{\circ}$ eccentricity.

\section{Discussion}

The data presented here expand on our previous report (Martin et al., 2001) and confirm that many of the properties of all cell classes (PC, MC, and KC blue-on) are qualitatively similar in peripheral compared with foveal retina. We first consider the spatial properties of peripheral ganglion cells in relation to known retinal anatomy then show how our data regarding $\mathrm{M} / \mathrm{L}$ cone opponency in the peripheral retina can be related to previous studies. Finally, we consider the relationship of our results to visual psychophysics and perception.

\section{Spatial properties of peripheral cells}

The receptive field center radii of $\mathrm{PC}, \mathrm{MC}$, and $\mathrm{KC}$ blue-on cells in peripheral retina (Figs. $2 D, 14$ ) are broadly consistent with the dendritic field size of their probable anatomical substrates in the midget, parasol, and small bistratified cell classes (Dacey and Lee, 1994). There is a greater separation of MC and PC center sizes than in foveal retina (Fig. $2 D$ ). The overlap of center size in the fovea is attributable to the expansion of center size of PC cells, beyond that expected of a single cone, by the point-spread function of the eye (Lee and Dacey, 1997). With the larger dendritic fields of peripheral MC and PC cells, the point-spread function, which changes less with eccentricity, plays a smaller role, and the center size of PC and MC cells is clearly distinct (Fig. 2B). We did not see any examples of red-green opponent cells with large, coextensive chromatic opponent subregions [type II (Wiesel and Hubel, 1966; Dreher et al., 1976)], but the presence of a sparse population of such cells could not be ruled out given the small sample size.

The KC blue-on receptive fields are customarily described as possessing type II receptive fields. Our data are broadly consistent with this idea (Fig. 14B). However, the $\mathrm{M}+\mathrm{L}$-cone input reliably has a slightly larger diameter than the S-cone input, which is surprising considering that the effect of chromatic aberration would be expected to enlarge the S-cone region relative to the $\mathrm{M}+\mathrm{L}$ region (Cottaris, 2003). Conversely, the result is consistent with the demonstration of small "hot spots" of S-cone input to the receptive fields of blue-on cells measured in an in vitro preparation of macaque retina (Chichilnisky and Baylor, 1999). In summary, we do not find clear evidence for exact matching of the spatial dimensions of chromatic opponent inputs to either PC or KC blue-on cells to form type II receptive fields. Nevertheless, a dedicated study of spatiochromatic receptive fields in primate retina is still needed to address this question systematically.

\section{Relationship to previous studies}

De Monasterio and Gouras (1975) described a small number of red-green opponent tonic (presumed PC pathway) cells between $10^{\circ}$ and $20^{\circ}$, and De Monasterio et al. (1975) reported that the proportion of concealed opponent cells increased toward the periphery, consistent with an increase in variability of cone weighting to PC cells, as seen in the present study (Fig. 7B). Zrenner and Gouras (1983) reported a consistent result. The presence of redgreen opponent responses in our sample, in both PC and MC cells, confirms that ML cone-selective mechanisms are present, at least to $40^{\circ}$ eccentricity, but the fundamental mechanism for MLselective circuitry remains unknown in either foveal or peripheral retina. Theoretical analysis showed that cone selectivity in the surround mechanism is not a prerequisite for spectral opponent properties (Lennie et al., 1991), and the result shown here in Figure 9 is consistent with this prediction for peripheral PC cells. Other calculations show that some degree of surround specificity can improve the signal-to-noise ratio for chromatic contrast detection, but complete specificity brings little additional benefit (Lee, 2004). Likewise, in agreement with data from foveal receptive fields (Lee et al., 1998; Reid and Shapley, 2002), our data are consistent with the presence of cone selectivity in the center 
mechanism of PC receptive fields, but the presence of some contamination by the wrong cone type cannot be ruled out.

Diller et al. (2004) reported on cone weightings from peripheral ganglion cells recorded in an in vitro preparation. They found that PC cells very rarely showed M/L-cone opponent input and saw little sign of frequency-doubled responses in MC cells. Although we cannot explain the lack of this sign of chromatic input to MC cells in the in vitro preparation, our data from PC cells may be less inconsistent with Diller et al.'s result than appears at first sight. We found that approximately one-quarter of all PC cells at the eccentricity range for our recordings (mean $\pm \mathrm{SD}, 32.5 \pm$ $7.62^{\circ} ; n=37$ ) showed non-opponent M/L cone input. The eccentricity of Diller et al.'s PC-cell sample was greater (mean \pm $\mathrm{SD}, 50.8 \pm 9.85^{\circ} ; n=26$ ) (O. Packer, personal communication), and current knowledge of retinal wiring would predict a concomitant increase in the proportion of non-opponent cells. More importantly, these authors made nearly all of their measurements at $9.7 \mathrm{~Hz}$ modulation frequency, at which we also find nonopponent response signature in the majority of PC cells (Figs. $7 C$, 9). Diller et al. did report non-opponent responses in three PC cells that were tested at $4.8 \mathrm{~Hz}$, but, as our results show, data from a larger sample of cells, tested at lower temporal frequencies, would be required to draw conclusions about chromatic specificity in PC cells at high eccentricities. Specifically, our linear model shows that measurements made at a single temporal frequency cannot predict the luminance or chromatic responsivity in PC cells at other frequencies (Figs. 8-10). This is because these properties are influenced not simply by center-surround interaction but by a combination of temporal filtering and temporal resonance ("under-damped filter") effects in the pre-ganglion cell circuitry. Given the large body of psychophysical evidence that the temporal-frequency range below $5 \mathrm{~Hz}$ is most relevant for human color vision (Kelly and van Norren, 1977; Swanson et al., 1987), we suggest that it will be important to explore this frequency range thoroughly in future studies of chromatic properties of peripheral ganglion cells.

\section{Relationship to psychophysical data}

There is a dramatic reduction in visual acuity with increasing eccentricity (Wertheim, 1894; Levi et al., 1985), and psychophysical data at different eccentricities can often be unified by scaling stimuli according to a cortical magnification factor (Tootell et al., 1988; Wässle et al., 1990). Although there is also a long history of studies on color sensation in the peripheral retina (for review, see Wade, 2000), it is only relatively recently that peripheral color sensation has been studied using appropriately scaled stimuli (Noorlander et al., 1983; Abramov et al., 1991; Mullen, 1991; Mullen and Kingdom, 2002). For example, Mullen and Kingdom (2002) showed that red-green psychophysical sensitivity decreases markedly with eccentricity, whereas blue-yellow and achromatic sensitivities remain relatively unchanged.

Our data show little change in chromatic sensitivity of blue-on cells with increasing eccentricity, in parallel with these psychophysical findings. However, the psychophysical loss of red-green sensitivity in peripheral retina was not paralleled by reduced redgreen sensitivity of peripheral PC cells. The proposal (Mullen and Kingdom, 1996) that the loss of psychophysical sensitivity is attributable to a uniform loss of cone opponency in PC cells is thus made unlikely. Conversely, our data do suggest that several factors would reduce the quality of $\mathrm{M} / \mathrm{L}$ opponent signals in peripheral retina. There is greater phase dispersion in the PC-cell population response (Fig. $7 B, C$ ), the temporal-frequency range for chromatic selectivity in PC cells is reduced (Fig. 9), and the pro- portion of cells showing opponent responses is reduced (Fig. 7C). We advance the following speculation regarding the relevance of these facts for central mechanisms of color vision.

During evolution, cortical mechanisms have developed by which $\mathrm{M}$ - and L-cone signals are distinguished, despite these signals being mixed within on- and off-center midget ganglion cell matrices (e.g., both M- and L-cone centers are present in oncenter PC cells). Such cortical mechanisms rely on temporal and spatial coherence of neuronal signals to develop appropriate connections and functional circuits (Wiesel, 1982; Singer, 1995). Our results imply that, for chromatic variation, both temporal and spatial coherence in the PC afferent pathway would be weaker in peripheral than in foveal retina. This raises the possibility that the capacity to distinguish L- and M-cone chromatic signatures has only been achieved, with an ecologically useful degree of spatial precision, for foveal vision.

\section{References}

Abramov I, Gordon J, Chan H (1991) Color appearance in the peripheral retina: effects of stimulus size. J Opt Soc Am A 8:404-414.

Anderson SJ, Mullen KT, Hess RF (1991) Human peripheral spatial resolution for achromatic and chromatic stimuli: limits imposed by optical and retinal factors. J Physiol (Lond) 442:47-64.

Benardete EA, Kaplan E (1997) The receptive field of the primate P retinal ganglion cell. I. Linear dynamics. Vis Neurosci 14:169-186.

Blessing EM, Forte J, Jusuf PR, Szmajda BA, Martin PR (2004) Spatial tuning of red-green responses of parvocellular cells in dichromatic and trichromatic marmosets. Proc Aust Neurosci Soc 15:22.

Calkins DJ, Tsukamoto Y, Sterling P (1998) Microcircuitry and mosaic of a blue-yellow ganglion cell in the primate retina. J Neurosci 18:3373-3385.

Chichilnisky EJ, Baylor DA (1999) Receptive-field microstructure of blueyellow ganglion cells in primate retina. Nat Neurosci 2:889-893.

Cottaris NP (2003) Artifacts in spatiochromatic stimuli due to variations in preretinal absorption and axial chromatic aberration: implications for color physiology. J Opt Soc Am A Opt Image Sci Vis 20:1694-1713.

Croner LJ, Kaplan E (1995) Receptive fields of P and M ganglion cells across the primate retina. Vision Res 35:7-24.

Crook JM, Lange-Malecki B, Lee BB, Valberg A (1988) Visual resolution of macaque retinal ganglion cells. J Physiol (Lond) 396:205-224.

Dacey DM, Lee BB (1994) The "blue-on" opponent pathway in primate retina originates from a distinct bistratified ganglion cell type. Nature 367:731-735.

De Monasterio FM, Gouras P (1975) Functional properties of ganglion cells of the rhesus monkey retina. J Physiol (Lond) 251:167-195.

De Monasterio FM, Schein SJ (1980) Protan-like spectral sensitivity of foveal Y ganglion cells of the retina of macaque monkeys. J Physiol (Lond) 299:385-396.

De Monasterio FM, Gouras P, Tolhurst DJ (1975) Concealed colour opponency in ganglion cells of the Rhesus monkey retina. J Physiol (Lond) 251:217-229.

Derrington AM, Lennie P (1984) Spatial and temporal contrast sensitivities of neurones in lateral geniculate nucleus of macaque. J Physiol (Lond) 357:219-240

Derrington AM, Krauskopf J, Lennie P (1984) Chromatic mechanisms in lateral geniculate nucleus of macaque. J Physiol (Lond) 357:241-265.

Diller L, Packer OS, Verweij J, McMahon MJ, Williams DR, Dacey DM (2004) $\mathrm{L}$ and $\mathrm{M}$ cone contributions to the midget and parasol ganglion cell receptive fields of macaque monkey retina. J Neurosci 24:1079-1088.

Dreher B, Fukada Y, Rodieck RW (1976) Identification, classification and anatomical segregation of cells with X-like and Y-like properties in the lateral geniculate nucleus of Old-World primates. J Physiol (Lond) 258:433-452.

Enroth-Cugell C, Robson J (1966) The contrast sensitivity of retinal ganglion cells of the cat. J Physiol (Lond) 187:517-552.

Flitcroft DI (1989) The interactions between chromatic aberration, defocus and stimulus chromaticity: implications for visual physiology and colorimetry. Vision Res 29:349-360.

Frishman LJ, Freeman AW, Troy JB, Schweitzer-Tong DE, Enroth-Cugell C (1987) Spatiotemporal frequency responses of cat retinal ganglion cells. J Gen Physiol 89:599-628. 
Ghosh KK, Grünert U (1999) Synaptic input to small bistratified (blue-On) ganglion cells in the retina of a New World monkey, the marmoset Callithrix jacchus. J Comp Neurol 413:417-428.

Gouras P (1968) Identification of cone mechanisms in monkey ganglion cells. J Physiol (Lond) 199:533-547.

Gouras P, Zrenner E (1979) Enhancement of luminance flicker by coloropponent mechanisms. Science 205:587-589.

Hendry SHC, Reid RC (2000) The koniocellular pathway in primate vision. Annu Rev Neurosci 23:127-153.

Hochstein S, Shapley RM (1976) Linear and nonlinear spatial subunits in Y cat retinal ganglion cells. J Physiol (Lond) 262:265-284.

Kaplan E, Shapley RM (1982) X and Y cells in the lateral geniculate nucleus of macaque monkeys. J Physiol (Lond) 330:125-143.

Kelly DH, van Norren D (1977) Two-band model of heterochromatic flicker. J Opt Soc Am 67:1081-1091.

Kremers J, Lee BB, Pokorny J, Smith VC (1993) Responses of macaque ganglion cells and human observers to compound periodic waveforms. Vision Res 33:1997-2011.

Lankheet MJM, Lennie P, Krauskopf J (1998) Temporal-chromatic interactions in LGN P-cells. Vis Neurosci 15:47-54.

Lee BB (2004) Paths to colour in the retina. Clin Exp Optom 87:239-248.

Lee BB, Dacey DM (1997) Structure and function in primate retina. In: Color vision deficiencies (Cavonius CR, ed), pp 107-117. Dordrecht: Kluwer Academic.

Lee BB, Sun H (2003) The physiological origin of chromatic response components in cells of the magnocellular pathway. Invest Ophthalmol (ARVO abstracts) 44:E3250.

Lee BB, Valberg A, Tigwell DA, Tryti J (1987) An account of responses of spectrally opponent neurons in macaque lateral geniculate nucleus to successive contrast. Proc R Soc Lond Ser B Biol Sci 230:293-314.

Lee BB, Martin PR, Valberg A (1989) Nonlinear summation of M- and L-cone inputs to phasic retinal ganglion cells of the macaque. J Neurosci 9:1433-1442.

Lee BB, Pokorny J, Smith VC, Martin PR, Valberg A (1990) Luminance and chromatic modulation sensitivity of macaque ganglion cells and human observers. J Opt Soc Am A 7:2223-2236.

Lee BB, Martin PR, Valberg A, Kremers J (1993) Physiological mechanisms underlying psychophysical sensitivity to combined luminance and chromatic modulation. J Opt Soc Am A 10:1403-1412.

Lee BB, Pokorny J, Smith VC, Kremers J (1994) Responses to pulses and sinusoids in macaque ganglion cells. Vision Res 34:3081-3096.

Lee BB, Kremers J, Yeh T (1998) Receptive fields of primate retinal ganglion cells studied with a novel technique. Vis Neurosci 15:161-175.

Lennie P, Haake PW, Williams DR (1991) The design of chromatically opponent receptive fields. In: Computational models of visual processing (Landy MS, Movshon JA, eds), pp 71-82. Cambridge, MA: MIT.

Levi DM, Klein SA, Aitsebaomo AP (1985) Vernier acuity, crowding and cortical magnification. Vision Res 25:963-977.

Martin PR, White AJR, Goodchild AK, Wilder HD, Sefton AE (1997) Evidence that blue-on cells are part of the third geniculocortical pathway in primates. Eur J Neurosci 9:1536-1541.

Martin PR, Lee BB, White AJR, Solomon SG, Rüttiger L (2001) Chromatic sensitivity of ganglion cells in the peripheral primate retina. Nature 410:933-936.

Mullen KT (1991) Colour vision as a post-receptoral specialization of the central visual field. Vision Res 31:119-130.

Mullen KT, Kingdom FA (1996) Losses in peripheral colour sensitivity pre- dicted from "hit and miss" post-receptoral cone connections. Vision Res 36:1995-2000.

Mullen KT, Kingdom FA (2002) Differential distributions of red-green and blue-yellow cone opponency across the visual field. Vis Neurosci 19:109-118.

Noorlander C, Koenderink JJ, Den Ouden RJ, Edens BW (1983) Sensitivity to spatiotemporal colour contrast in the peripheral visual field. Vision Res 23:1-11.

Reid RC, Shapley RM (2002) Space and time maps of cone photoreceptor signals in macaque lateral geniculate nucleus. J Neurosci 22:6158-6175.

Schiller PH, Malpeli JG (1977) Properties and tectal projections of monkey retinal ganglion cells. J Neurophysiol 40:428-445.

Singer W (1995) Development and plasticity of cortical processing architectures. Science 270:758-764.

Smith VC, Pokorny J (1975) Spectral sensitivity of the foveal cone photopigments between 400 and $500 \mathrm{~nm}$. Vision Res 15:161-171.

Smith VC, Lee BB, Pokorny J, Martin PR, Valberg A (1992) Responses of macaque ganglion cells to the relative phase of heterochromatically modulated lights. J Physiol (Lond) 458:191-221.

Smith VC, Pokorny J, Lee BB, Dacey DM (2001) Primate horizontal cell dynamics: an analysis of sensitivity regulation in the outer retina. J Neurophysiol 85:545-558.

Solomon SG, Martin PR, White AJR, Rüttiger L, Lee BB (2002) Modulation sensitivity of ganglion cells in peripheral retina of macaque. Vision Res 42:2893-2898.

Swanson WH, Ueno T, Smith VC, Pokorny J (1987) Temporal modulation sensitivity and pulse-detection thresholds for chromatic and luminance perturbations. J Opt Soc Am A 4:1992-2005.

Thibos LN (1987) Calculation of the influence of lateral chromatic aberration on image quality across the visual field. J Opt Soc Am A 4:1673-1680.

Tootell RBH, Switkes E, Silverman MS, Hamilton SL (1988) Functional organization of macaque striate cortex. II. Retinotopic organization. J Neurosci 8:1531-1568.

Wade NJ (2000) A natural history of vision. Cambridge, MA: MIT.

Wässle H, Grünert U, Röhrenbeck J, Boycott BB (1990) Retinal ganglion cell density and cortical magnification factor in the primate. Vision Res 30:1897-1911.

Wertheim T (1894) Über die indirekte Sehschärfe. Zeitschrift für Psychologie und Physiologie des Sinnesorgane 7:172-187.

White AJR, Sun H, Swanson WH, Lee BB (2002) An examination of physiological mechanisms underlying the frequency-doubling illusion. Invest Ophthalmol Vis Sci 43:3590-3599.

Wiesel TN (1982) Postnatal development of the visual cortex and the influence of environment. Nature 299:583-591.

Wiesel TN, Hubel DH (1966) Spatial and chromatic interactions in the lateral geniculate body of the rhesus monkey. J Neurophysiol 29:1115-1156.

Yeh T, Lee BB, Kremers J (1995a) Temporal response of ganglion cells of the macaque retina to cone-specific modulation. J Opt Soc Am A Opt Image Sci Vis 12:456-464.

Yeh T, Lee BB, Kremers J, Cowing JA, Hunt DM, Martin PR, Troy JB (1995b) Visual responses in the lateral geniculate nucleus of dichromatic and trichromatic marmosets (Callithrix jacchus). J Neurosci 15:7892-7904.

Zrenner E, Gouras P (1981) Characteristics of the blue sensitive cone mechanism in primate retinal ganglion cells. Vision Res 21:1605-1609.

Zrenner E, Gouras P (1983) Cone opponency in tonic ganglion cells and its variation with eccentricity in rhesus monkey retina. In: Colour vision: physiology and psychophysics (Mollon JD, Sharpe LT, eds), pp 211-223. London: Academic. 